\title{
MISCIBLE DISPLACEMENT OF 2,4-D HERBICIDE DURING CONSTANT LIQUID FLOW VELOCITY INTO INITIALLY DRY SOILS
}

\section{By}

Veerabhadrappa Jyothi

A DISSERTATION PRESENTED TO THE GRADUATE COUNCIL OF THE UNIVERSITY OF FLORIDA IN PARTIAL FULFILLMENT OF THE REQUIREMENTS FOR THE DEGREE OF DOCTOR OF PHILOSOPHY

\section{UNIVERSITY OF FLORIDA}




\section{ACKNOWLEDGEMENTS}

On the outset, I would like to express deep appreciation to Dr. Luther C. Hammond, Chairman of the Supervisory Committee and to Dr. Robert S. Manse11, Co-chairman for their valued counse1, guidance, assistance and above all for my continued moral support during the entire duration of the program.

I am indebted to Dr. David S. Anthony, Dr. Allen R. Overman and Dr. Charles H. Van Middlelem for their interest, constructive review of this manuscript and participation on the supervisory committee.

Sincere gratitude is expressed to Dr. Charles F. Eno, Chairman, Soil Science Department, for arranging the facilities towards graduate studies.

Special thanks are due for Dr. Lewis E. Johns, Jr., in helping to cope with difficulties in mathematical models and to Mr. Richard M. McCurdy for his valued help in programing the calculations.

I am grateful to the Florida Water Resources Research Center for financial support, under agreement OWRR project number A-013-FLA and Soil Science Department for partial support.

I would like to commend Mrs. Mary Ann Phillips for typing the first draft and Mrs. Grace Beal for her excellent typing and proofing of the final product.

I sincerely wish to bestow tribute and thanks to my wife, Ambuja, for her companionship, understanding and devoted assistance in ny work and to our children, Prashant and Pratima, just for what they are. 
ACKNOWLEDGEMENTS . . . . . . . . . . . . . . . . . . . . ii

LIST OF TABLES . . . . . . . . . . . . . . . . . . . . iv

LIST OF FIGURES. . . . . . . . . . . . . . . . . . v v

ABSTRACT ......................... vii

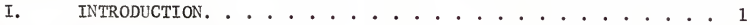

II. REVIEW OF LITERATURE. . . . . . . . . . . . . . 3

Historical ................... 3

Factors Influencing Transport of Herbicides. . . . . 5

Diffusion Through Soil Air .......... 5

Diffusion Through Soil Water......... 7

Flow with Moving Water............ 11

Adsorption . . . . . . . . . . . . . . 14

Mathematica 1 Models. . . . . . . . . . . . . 17

Thermodynamic Mode1. . . . . . . . . . . . . 17

Capillary Tube Mode1............ . . 18

Chromatographic Mode1. . . . . . . . . . . 19

III. THEORETICAL . . . . . . . . . . . . . . . . 22

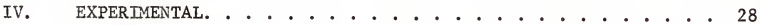

Introduction................. . . 28

Soils.................... . 28

Physica 1 Set-up of Flow System ........... . 30

Preparation and Analysis of Herbicide Solution. . . . . 34

Adsorption Isotherms . . . . . . . . . . . 37

V. RESULTS AND DISCUSSION. . . . . . . . . . . 38

Degradation of 2,4-D in the Columns. . . . . . . 60

Adsorption of 2,4-D on Soils . . . . . . . . . 66

Movement of 2,4-D in glass beads.......... 66

Movement of 2,4-D in the Soils ........... 69

Elution of 2,4-D through Lakeland find sand. . . 70

Elution of 2,4-D through Fellowship subsoil. . . 71

Elution of 2,4-D through Everglades mucky peat ... 72 
Page

VI. SUMMARY AND CONCLUSIONS .................... 94

APPENDIX . . . . . . . . . . . . . . . . 98

LITERATURE CITED. . . . . . . . . . . . . . . 101

BIOGRAPHCAL SKETCH . . . . . . . . . . . . . 108 
2. Scintillation mixture for counting radioactivity

in aqueous samples............ . . 35

3. Selected physical properties of soil materials

and glass beads. . . . . . . . . . . 39

4. Coefficient $m$ for 2,4-D on different soil

materials at equilibrium .......... 46

5. Percentage recovery of $2,4-D$ in the effluent from

glass beads during displacement. . . . . . . 79

6. Percentage recovery of 2,4-D in the effluent from

Lakeland fine sand during displacement . . . . 81

7. Percentage recovery of 2,4-D in the effluent from

Fellowship subsoil during displacement . . . . 82

8. Percentage recovery of 2,4-D in the effluent from

Everglades mucky peat during displacement. .... 83

9. $R_{f}$ values of 2,4-D for four soils during the

displacement at the flow velocities........ 84 


\section{LIST OF FIGURES}

The general set-up of soil column during the displacement studies............ 31

2

3

Schematic of sampling system for extracting 25 microliter of soil solution............... 33

Results of thin layer chromatograph analyses for 2,4-D on selected effluent samples from glass beads, Lakeland fine sand, Fellowship subsoil and Everglades mucky peat................ 40

Adsorption of 2,4-D herbicide on Fellowship subsoil Lakeland sand and glass beads. . . . . . . . 41

Adsorption of 2,4-D herbicide on Everglades mucky peat..................

Experimental and calculated relative concentration distribution of 2,4-D in glass beads at $30 \mathrm{~cm}$ length and $1.1 \mathrm{~cm} / \mathrm{h}$ flow velocity across the cross section. . 44

Experimental and calculated relative concentration distribution of 2,4-D in glass beads at $15 \mathrm{~cm}$ length and $1.1 \mathrm{~cm} / \mathrm{h}$ flow velocity across the cross section. . 45

Experimental and calculated relative concentration distribution of 2,4-D in glass beads at $30 \mathrm{~cm}$ length and $2.2 \mathrm{~cm} / \mathrm{h}$ velocity across the cross section. . . 46

Experimenta 1 and calculated relative concentration distribution of 2,4-D in glass beads at $15 \mathrm{~cm}$ length and $2.2 \mathrm{~cm} / \mathrm{h}$ velocity across the cross section... . 47

Experimenta 1 and calculated relative concentration distribution of 2,4-D in Lakeland fine sand at $30 \mathrm{~cm}$ length and $1.1 \mathrm{~cm} / \mathrm{h}$ velocity across the cross

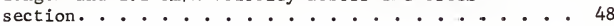


Experimental and calculated relative concentration distribution of 2,4-D in Lakeland fine sand at $30 \mathrm{~cm}$ length and $2.2 \mathrm{~cm} / \mathrm{h}$ velocity across the cross section. . 60

Experimental and calculated relative concentration distribution of 2,4-D in Lakeland fine sand at $15 \mathrm{~cm}$ length and $2.2 \mathrm{~cm} / \mathrm{h}$ velocity across the cross section.... 62

Experimental and calculated relative concentration distribution of 2,4-D in Fellowship subsoil at $30 \mathrm{~cm}$ length and $1.1 \mathrm{~cm} / \mathrm{h}$ velocity across the cross section.....

Experimental and calculated relative concentration distribution of 2,4-D in Fellowship subsoil at $15 \mathrm{~cm}$ length and $1.1 \mathrm{~cm} / \mathrm{h}$ velocity across the cross section ... . 66

Experimental and calculated relative concentration distribution of 2,4-D in Fellowship subsoil at $30 \mathrm{~cm}$ length and $2.2 \mathrm{~cm} / \mathrm{h}$ velocity across the cross section... . 68

17 Experimenta1 and calculated relative concentration distribution of 2,4-D in Fellowship subsoil at $15 \mathrm{~cm}$ length and $2.2 \mathrm{~cm} / \mathrm{h}$ velocity across the cross section... . 70 tribution of 2,4-D in Everglades mucky peat at $30 \mathrm{~cm}$ length and $1.1 \mathrm{~cm} / \mathrm{h}$ velocity across the cross section. . 72

Experimental and calculated relative concentration distribution of 2,4-D in Everglades mucky peat at $15 \mathrm{~cm}$ length and $1.1 \mathrm{~cm} / \mathrm{h}$ velocity across the cross section. . 74

20 Experimental and calculated relative concentration distribution of 2,4-D in Everglades mucky peat at $30 \mathrm{~cm}$ length and $2.2 \mathrm{~cm} / \mathrm{h}$ velocity across the cross section. . 76

21 Experimental and calculated relative corcentration distribution of 2,4-D in Everglades mucky peat at $15 \mathrm{~cm}$ length and $2.2 \mathrm{~cm} / \mathrm{h}$ velocity across the cross section. . 78 
A Dissertation Presented to the Graduate Council of the University of Florida in Partial Fulfillment of the Requirements for the Degree of Doctor of Philosophy

\section{MISCIBLE DISPLACEMENT OF 2,4-D HERBICIDE DURING CONSTANT LIQUID FLOW VELOCITY INTO INITIALLY DRY SOILS}

By

Veerabhadrappa Jyothi

August, 1971

Chairman: Dr. L. C. Hammond

Co-chairman: Dr. R. S. Mansell

Major Department: Soil Science

A theoretical model was developed to predict the movement of organic chemicals through porous materials packed in columns of finite length. Movement due to diffusion was assumed to be negligible. The model is based on the following assumptions: transport of solute results primarily by mass flow; adsorption occurs as a first order reaction; and adsorption isotherms are linear.

The theory was tested by studying the movement of ${ }^{14} \mathrm{C}$ labeled 2,4-D (2,4-dichlorophenoxyacetic acid herbicide through glass beads (105-210 $\mu$ ), Lakeland fine sand, Fellowship subsoil, and Everglades mucky peat, under constant flow velocities. Air-dry soils were packed uniformly in a column which was held vertical during the studies. A dilute solution of 2,4-D was introduced at the bottom of the column, with constant liquid flux maintained at $50 \mathrm{ml} / \mathrm{h}$ with a positive displacement pump. The same flux was continued until $200 \mathrm{ml}$ of solution was introduced, at which time solution was immediately replaced by pure water containing $0.5 \%$ phenol. Thus, "volume slug" of herbicide solution was displaced upward in the column by water at the same flow rate. Studies were also made at a liquid flux of $100 \mathrm{~m} / \mathrm{h}$. Effluent was collected in fractions for 
analyses. Soil solution was extracted midway of the column with a specially constructed device using a porous plate and partial vacuum. The extract was collected periodically in amounts of 25 microliters. Effluent samples and the extracts were analyzed for 2,4-D content with a liquid scintillation counting system. Random effluent samples were subjected to additional analyses for 2,4-D to determine if the herbicide was degraded in the soil columns. The analyses were done by thin layer chromatography. It was found from the thin layer chromatographic studies that the herbicide did not disintegrate during transport.

Theoretical and experimental curves of herbicide concentration as a function of accumulative volume of solution introduced at the bottom of the columns, were plotted for effluent and soil extracts at both velocities. It was observed that the theoretical curves compared fairly wel1 with experimenta1 results. However, some discrepancy was observed between calculated and experimental curves during the initial time periods. Calculated concentrations were higher than the observed concentrations in the effluent. This indicated that there was higher adsorption on the porous material during wetting stage since all the surface area was readily available for adsorption.

Observed concentrations were slightly higher than the calculated values near the tail end of the curve. This prolonged skewness was attributed to diffusion which is $1 i k e 1 y$ to show in the long run but the simplified model omitted it. In addition, hysteresis may exist in the partition ccefficient during adsorption and desorption. Calculated and the observed peaks of maximum herbicide concentration were reached almost within the same time intervals. This mainly depended upon the partition coefficient determined in the adsorption isotherms. The rate of adsorption 
seems to affect the spreading of the breakthrough curves.

The herbicide moved readily through the glass beads, Lakeland fine sand and Fellowship subsoil. Most of the herbicide was recovered within two pore volumes of effluent in these soils. Movement was very mcuh hindered in Everglades mucky peat. It took more than 5 pore volumes to recover only 60 percent of applied 2,4-D. Irreversible adsorption of 2,4-D also seemed to occur in the organic soils but not on the mineral soils. 


\section{INTRODUCTION}

The number of herbicides manufactured and recommended for application has been increasing every year at a phenomenal rate. The use of herbicides has been so specialized that almost any and every unwanted flora can be eliminated from the fields, leaving just the main crop. The growing chemical technology is facing a dilemma at the general public awakening towards protecting the environment. These chemicals have been accused of polluting waterways and leaving residues in soils thereby injuring subsequent crops (Sheets and Harris, 1965; Roadhouse and Birk, 1961; and Upchurch, 1966). In the view of many enlightened people, the awesome edifice of modern technology is in danger of becoming more a milestone than a spire. Herbicides which have been considered most useful by the farming public have also been the primary target of the critics.

When a herbicide is applied to the soil, for the purpose of killing undesirable vegetation, some side effects are expected. These effects may directly influence one or more kinds of the micro-organisms that inhabit the soil. The disturbance of microbial populations might ultimately affect fertility adversely. However, such a threat to micro-organisms from the norma 1 selective weed killers is inconsequential according to Chandra et a1., 1960, and Shennan and Fletcher, 1965. This cannot hold good generally for each new herbicide. Furthermore, Upchurch (1966) notes that if soil sterilant rates are used, the herbicide effects on the microorganisms are more likely to be found. They are usually organic compounds and like any substance are subjected to physica1, chemical and biological 
forces. Soil is one of the most potent agents in deciding the fate of herbicides.

Every soil applied herbicide undergoes a pattern of dissipation depending on the properties of the herbicide, soil and the prevailing environmenta1 conditions. Freed et a1., 1962, listed the following factors that affect persistence and movement of herbicides in the soil:

1. Adsorption on the surface of soil colloids.

2. Removal by leaching and surface runoff.

3. Volatilization into atmosphere.

4. Chemica1 and microbial breakdown.

5. Removal by plants.

A theory was proposed to describe and predict movement of 2,4dichlorophenoxyacetic acid $(2,4-D)$ when applied as a dilute solution to initially dry soils and displaced by water. The test of the theory was conducted in soils packed into columns of finite length. 


\section{REVIEW OF LITERATURE}

\section{Historica1}

The art and science of weed control is relatively young although the problem of weeds has been in existance ever since the first man wandered the earth. Timmons (1970) cites that Adam was promised thurns and thistles (Genesis 3:18). However, available evidence and logic indicates that early man did not consciously or intentionally practice weed contro. H. G. Wells (1961) feels that primitive agriculture was begun by neolithic man sometime between 15,000 and 10,000 B. C. The first actual planting of crops probably was growing of primitive wheat and the unwanted plants (weeds) were removed manual1y.

The control of weeds was done incidentally and not intentionally. Timmons (1970) in his exhaustive and inspirational review of over 200 citations describes the development of concepts about and control of weeds. The general philosophy appears to be that weeds were a curse which must be endured and about which little could be done except by that which was incidental to crop production and laborious supplemental hand methods. Remnants of that philosophy were still present in early 1900 's a1though Jethro Tu11 in the 18 th century urged extermination of weeds in Britain. He was a crusader against weeds.

Man apparently used chemicals for the control of insects and plant diseases much earlier than he did for the control of weeds. Use of wine for wheat seed treatment for controlling mildew in $60 \mathrm{~A}$. D., sulfur against plant discases in 1350 and Paris green against insects in 1867 
is documented by the National Agricultural Chemicals Association (1958).

Hildebrand (1946) has discussed the early herbicide developments. Most early herbicides were comprised of inorganic materials. Lime and common salt (sodium chloride) are known to have been recommended in Germany for destroying horse tail and orange hawkweed, respectively. Common salt was used extensively for field bindweed control on highway and railroad rights-of-way in Kansas as late as 1937-1950 (Yost, 1940). Other inorganic chemicals used at times were copper sulfate, iron sulfate, sulfuric acid and nitric acid. By 1935 sulfuric acid was used as a selective herbicide in onions and to some extent in cereals (Ball and French, 1935).

Conscientious development of new herbicides has progressed steadily since 1900. The advent of organic herbicides was greatly responsible for much of this progress. The discovery of weed-killing properties of the phenoxy acetic herbicides during 1942 to 1944 (Hamner and Tukey, 1944) marked the real beginning of the herbicide phase of the "Chemical Era of Agriculture." Peterson (1967) presents the complete history of the development and use of 2,4-D and related growth-regulating chemicals beginning from 1935. Credit for the discovery of 2,4-D is given to Zimmerman and Hitchcock of Boyce Thompson Institute.

The market for chemical herbicides since the discovery of 2,4-D has grown at a phenomenal rate. Peterson (1967) notes, "In 1940, the estimated market for herbicides came to only $\$ 1.5$ to $\$ 2$ million; in 1962 , American farmers treated over $70,000,000$ acres at a tota 1 cost of $\$ 270,750,000$. Without doubt 2,4-D precipitated this phenomenon, bringing unexpected success to a half century of agricultural and botanical research."

The production of new agricultural chemicals, mostly organic compounds after 1950 and the screening of thousands of these against 
weeds resulted in approximately 120 herbicides being thoroughly tested and included in the Weed Science list of common and chemical names by 1969 (Timmons, 1970).

\section{Factors Influencing Transport of Herbicides}

Herbicides are applied to the soil surface for the purpose of killing pre-emergence weeds. The foliar applied herbicides also reach the soil surface. In either case, they are subjected to various transport and dissipation processes (Freed et a1., 1962), such as biological assimilation and degradation, chemical degradation, precipitation, diffusion, adsorption and flow with water. Transport of herbicides is influenced by the properties of soil and those of herbicides along with the weather, rate of application and other surrounding conditions.

The following discussion will be restricted to physical phenomena involved in the transport of herbicides in the absence of other factors. These physical mechanisms are: diffusion through soil air, diffusion through soil water, flow with moving water, and adsorption.

\section{Diffusion Through Soil Air}

Diffusion through soil air is of importance in the movement of volatile and gaseous substances like Lindane and methyl bromide which have relatively large vapor pressures. The basic theory of diffusion processes has received much attention since the proposal of Fick's first and second laws, dating back to 1855 (Jost, 1960). These two fundamental laws of diffusion in one dimension are represented as:

$$
Q=-D \frac{d c}{d x}
$$


and $\quad \frac{\partial c}{\partial t}=D \frac{\partial^{2} c}{\partial x^{2}}$

where $Q=\operatorname{diffusion} \mathrm{flux} M / \mathrm{L}^{2} \mathrm{~T}$

$$
\begin{aligned}
& D=\text { coefficient of diffusion } \mathrm{L}^{2} / \mathrm{T} \\
& \mathrm{c}=\text { concentration } \mathrm{M} / \mathrm{L}^{3} \\
& \mathrm{t}=\text { time } \mathrm{T} \\
& \mathrm{x}=\text { distance oriented along } \mathrm{X} \text {-axis } \mathrm{L}
\end{aligned}
$$

The coefficient D so defined is for open, uniform and unobstructed air. This diffusion coefficient will not be the same for soils because the actual diffusion pathways available for diffusion are tortuous and thus longer than the direct distance. Hartley (1964) notes that these paths are also of non-uniform cross sectional area. For this reason it is necessary to introduce the so-called tortuosity factor. Buckingham (1904) estimated the diffusion of carbon dioxide in soil to be equal to unobstructed diffusion in the porous space in soil. In other words, the diffusion in a soil column is the product of diffusion in free air and the fraction of volume not occupied by solids. Penman (1940) found a tortuosity factor of about 0.6 for a variety of soils and degrees of packing of glass beads. Call (1957) arrived at a ratio $\mathrm{D} / \mathrm{D}_{0}$ given as

$$
\mathrm{D} / \mathrm{D}_{\mathrm{O}}=0.66(\mathrm{E}-0.1) \quad 2.3
$$

where $\mathrm{E}$ is the fraction of total bulk soil volume occupied by air. $D$ is the diffusion coefficient for transport through a porous medium and $D_{0}$ is the coefficient for free diffusion. Equation 2.3 implies that no diffusion occurs for values of $\mathrm{E}$ of 0.1 or less. Diffusion and mixing of gases play an important role in the distribution of gases when one gas is displacing the other. This was studied by Rolston et a1. (1969) using miscible displacement techniques. For herbicides with relatively low vapor pressures transport by diffusion through soil air is normally considered 
to be insignificant.

\section{Diffusion Through Soil Water}

Diffusion of water-soluble substances in soil water medium has been studied by several workers such as Hartley (1960, 1964), Porter et al. (1960), Logan et al. (1953), Stewart and Eck (1958), Del Pozo (1959), Tyler et a1. (1958), Upchurch and Pierce (1957), Harris (1964), Phillips and Brown (1968), Phillips (1969) and Peaslee and Phillips (1970).

It is well established experimentally (Hartley, 1964) that the tortuosity factor does not vary greatly among different soils. The magnitude of this factor is approximately the same regardless of whether air or water is the diffusion medium, as long as the medium fills the spaces between the particles. In other words tortuosity factor for watersaturated soil has approximately the same magnitude as that for air-dry soil. In normal agricultural soils however, water occupies only part of the volume (water-unsaturated soil) between the particles, the rest being air filled. At some finite moisture content characteristics of the pore size distribution, water becomes less continuous than air.

Klute and Letey (1958) conducted a study of ionic diffusion of ${ }^{86} \mathrm{RbCl}$ through $200 \mu$ diameter glass beads at different moisture levels. The $\mathrm{D} / \mathrm{D}_{\mathrm{o}}$ decreased from 0.45 at 33 percent moisture on volume basis to 0.05 at 20 percent moisture content. This indicates that considerable reduction in the tortuosity factor is due to the discontinuities at several points of contact so the actual path is longer along the water film on the minerals. Stewart and Eck (1958) studied the extent of movement of surface-applied nitrate into Tillman clay loam soil that had been adjusted to each of five different moisture levels. The soil was incubated at constant temperature for 14 days and the nitrate determinations 
were made on samples taken from different depths. They found that nitrate had moved downward 2.5 inches when the soil moisture was at near saturation and to 1.5 inches in all drier soil samples. At water contents of 18.2, 8.3 and 6.6 percents, about $14.8,5.5$ and 1.2 percents, respectively, of the originally applied nitrate was found below a depth of 1.5 inches. This movement of nitrate was attributed to diffusion in the soil water. Porter et a1. (1960) obtained a tortuosity factor by dividing the diffusion coefficient of chloride obtained for soil systems by the diffusion coefficient of chloride in pure water. They observed a linear increase in the tortuosity factor with moisture content. In a loam soil, the factor was zero at 9 percent but increased to 0.32 at 28 percent soil water by volume. For clay it was zero at 13 percent and increased to 0.28 at 44 percent soil water.

The tortuosity factor is dependent on moisture content and falls to zero at some lower moisture content. Hartley (1964) calculated that molecules of the size range of most organic herbicides will have molecular diffusion coefficients in free water of about $5 \times 10^{-6} \mathrm{~cm}^{2} / \mathrm{sec}$. In soils, at finite moisture content, diffusion coefficient was only one-fifth as large, that is $1 \times 10^{-7} \mathrm{~cm}^{2} / \mathrm{sec}$. The moisture content also affects the diffusional transport in other ways. Biggar and Nielsen (1967) commented that the viscosity and density of water are modified by the proximity of mineral surfaces and thus the free diffusion through the water films around the mineral particles will be considerably less.

Oddson et al. (1970) used a mathematical model to predict organic chemicals in soil solution at different depths and time. They assumed that movement of organic chemicals due to diffusion is negligible during the transport by flowing water. 
A fine textured soil that has no aggregations has a higher moisture holding capacity, than a course textured soil. Hence, at a given soil moisture content there is a difference in the continuity of water. Porter et al. (1960) observed by extrapolation that approximately 7, 10 and 15 percent water content brought about zero transmission for loam, silty loam, and clay, respectively. They assumed that at these moisture levels the continuity of water films was completely destroyed. The fact that the $\mathrm{D} / \mathrm{D}_{\mathrm{o}}$ extrapolates to zero at finite moisture contents for finer textured soils implies that diffusion of a chemical through soil adsorbed water is very small.

Most of the commercially important herbicides are sufficiently nonvolatile that their transport through soil water seems to be more important than transfer through soil air (Hartley, 1960). Diffusion through air may be ignored for all the herbicidal acids and for those having polar hydrophilic groups as noted by Hartley (1960).

Under prolonged static conditions of soil moisture or where the liquid percolation rate is very slow, diffusion may become important in distributing the chemicals through the soil profile. Logan et al. (1953) observed that radioactive isopropyl $\mathrm{N}$-phenyl carbamate (IPC) was further redistributed upon standing for long duration after the usual distribution resulting from leaching of soil columns.

Downward movement of surface applied nitrate in Tillman clay loam soil under certain moisture conditions in which liquid water was not moving, has been observed by Stewart and Eck (1958). The extent of downward movement was about two and a half inches when the soil was at moisture equivalent over a long period of time. Similar observations were made by Tyler et a1. (1958) with dissolved salts and by Del Pozo (1959) with 
trichloro-benzoic acid (TBA). Upchurch and Pierce (1957) showed that for a very slow percolation, water-dissolved chemicals tend to spread (undergo dispersion) due to diffusion.

Due to the large size of most organic herbicide molecules and their low solubility in water, diffusion over long distances is normally considered negligible. Harris (1964) observed that dicamba and diphenamid moved downward with percolating water and upward when free evaporation was permitted from the surface. The upward movement almost ceased when the soil was covered to prevent evaporation. Lack of movement in the covered soil suggested that the herbicide was carried with the water moving to the evaporating site and diffusion was negligible. Hartley (1960) calculated that when sparingly soluble herbicides were applied on the surface, several years would be necessary for as little as 1 percent to migrate by diffusion to a depth of two feet in a moist soil. Diffusion seems to be important over a distance of up to one $\mathrm{mm}$ from the source. Therefore, dispersion during convection is less dependent upon diffusion under conditions of rapid flow.

Oddson et al. (1970) have proposed a theoretical model to predict distribution of organic chemicals in both solution and adsorbed phases as a function of soil depth and time for various chemical and soil properties. They considered mainly adsorption, desorption, and flow velocity of water. Their model assumes that the rate of movement by mass transport greatly exceeds the diffusion component and so they neglected diffusion component of dispersion. There are, however, several herbicide movement studies reported using diffusion type coefficients (Lindstrom et al., 1967; Davidson et al., 1968, Davidson and Santelman, 1968; Kay and Elrick, 1967; and Green et al., 1968). 
Rhee and Amundson (1970) made a theoretical analysis of multicomponent adsorption in adiabatic adsorption columns. Their system also assumed negligible effects of dissusion and establishment of equilibrium between mobile and stationary phases of the solute.

Green et al. (1968) studied the transport of Atrazine in several soils as a function of reversible adsorption, liquid flow velocity, soil water content and biological degradation variables only. They observed elution from water-saturated columns was nearly the same at flow velocities of $0.6,3.5$, and $7.0 \mathrm{~cm} /$ hour. This led them to conclude that herbicide transport through these soils had little sensitivity to flow rate or prevailing water content.

Koren et al. (1969) observed the migration patterns of thiocarbamate herbicides which are volatile. Although the diffusion should predominate in this kind of chemical, they noticed that the chemical generally moved with the infiltrating water. Vapor losses were decreased mainly because of rapid infiltration, rapid drying of the spray solution, and an adsorptive complex capable of holding the herbicide.

\section{Flow With Moving Water}

Water flow in soils is the most important means by which herbicides and plant nutrients are transported in downward, upward or lateral directions. It has been shown that water can move the chemicals that are water-soluble, sparingly soluble, and even insoluble, through porous materials (Sherburne et a 1., 1956; Del Pozo, 1959; Phillips, 1959; Lambert et al., 1965;

Ogle and Warren, 1954; Upchurch and Pierce, 1957; Burnside et al., 1963.

Assume that a thin film of herbicide is sprayed upon the soil surface and then water is applied either by rain fall or by irrigation. Prior to 
applying the water al1 the herbicide is concentrated in a very narrow zone at the surface. As the water percolates down the profile, the herbicide begins to move downward and movement depends upon adsorption, solubility, size of the molecule and the velocity of water. Due to the above chemical properties of the herbicide, the soil zone of highest concentration will not move with the same velocity as the water but will lag behind the water flow. This gives rise to the development of a chromatogram as elicited by Purne11 (1962), Snyder (1968), and Giddings (1965). With increasing time the wetting front and zone of highest concentration becomes separated spatially, but movement of herbicide continues to be dominated by the moving water. Due to the adsorption and subsequent desorption and microscopic distribution of liquid velocity in soil pores, the concentration zone spreads or disperses within the soil profile (Sherburne et a1., 1956; and Lambert et a1., 1965).

Sherburne et a1. (1956) developed the following mathematical equation to determine the depth of maximum concentration in soil water for two soils:

$$
y=x \operatorname{Exp}\left(-\frac{c}{x}\right) \quad 2.4
$$

where $y=$ depth of concentration peak after 24 hours (inches)

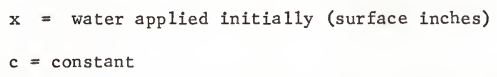

Freed (1958) using a thermodynamic approach suggested the equation:

$$
y=x \operatorname{Exp}\left(-\frac{\Delta H}{\operatorname{RTX}}\right) \quad 2.5
$$

where $\mathrm{x}$ and $\mathrm{y}$ are same as for 2.4

$$
\begin{aligned}
\Delta \mathrm{H} & =\text { enthalpy of adsorption (K. cal/mole) } \\
T & =\text { temperature }\left({ }^{\circ} \mathrm{K}\right) \\
\mathrm{R} & =\text { universal gas constant (K. cal/degree mole) }
\end{aligned}
$$


Similarities between the equations 2.4 and 2.5 are quite apparent. Freed et al. (1962) gave physical-chemical meaning to the arbitrary constant of Sherburne et al. (1956).

A similar exponential equation has been derived by Lambert et al. (1965).

Ogle and Warren (1954) made two types of herbicide movement studies: a) A percolation study designed to follow the movement through soil columns following the addition of a pre-determined amount of water, and b) A leaching study designed to determine the relative amounts of infiltration required to remove completely the herbicides from the surfaces of three types of soils. They tried to relate the degree of leaching with the molecular size, solubility and probable chemical reactions in the soil. They found that there was an interaction of herbicides and soil types in relation to herbicidal movement and retention. TCA moved rapidly compared to 2,4-D. There was a highly significant correlation between retention of NPA (N-1 Naphthyl phthalmic acid) and exchange capacity.

Upchurch and Pierce (1957) studied the effects of amount, frequency and intensity of rainfall in transport of monuron in Lakeland sand. They found that less intense rainfall resulted in greater accumulation of monuron near the surface. Frequent applications removed more herbicide from upper layers than did the less frequent applications. They concluded that less frequent applications allowed more moisture to evaporate from the soil surface and the herbicide moved with water during evaporation.

In field studies made by Burnside et al. (1963) 38 inches $(96 \mathrm{~cm}$ ) of rainfa11 was observed to be insufficient to remove all of the herbicide from the 3 to 24 inch $(7.6$ to $60 \mathrm{~cm})$ soil depth. 
When herbicides are applied in the form of solutions or emulsions to the soil followed by water, solute transport takes place mostly by the flowing water. This type of displacement has been of interest to scientists in the fields of not only soil science but also in chemistry and engineering. Although the phenomenon of chromatography has been usefully employed by chemists for separation, and identification of compounds, it has been a big stepping stone for understanding processes in other fields. Transport through the liquid phase has been referred to as hydrodynamic dispersion by Day (1956), and as miscible displacement by petroleum engineers and Nielsen and Bigger (1961) and as chromatographic separation by chemists. Hydrodynamic dispersion refers to spreading due to convection coupled with diffusion. Details on techniques employed will follow under the title "Models".

Using miscible displacement techniques the movement of several chemicals through soils have been studied by Davidson et al. (1968); Davidson and Santelman (1968); Kay and Elrick (1967); Green et al. (1968). In all these studies the flowing water under controlled conditions plays a major role in the movement of chemicals while the adsorption and desorption processes hinder and subsequently dampen the movement, and diffusion spreads the chemicals in the columns.

\section{Adsorption}

Adslrption is one of the most important processes that hinder the free movement of solution through porous materials. The phenomenon of adsorption has been recognized since the early days of chromatography and been used in the separation and detection of various organic compounds (Martin and Synge, 1941). For the case of liquid chromatography, the process of adsorption is described by Giddings (1965) as the movement of 
a solute-laden mobile phase through the stationary porous material. During this migration, the solute molecules continuously exchange from the solution to the adsorbent and from the adsorbent back into the solution phase. Going from the solution to adsorbent is termed as sorption, while coming back into solution is termed desorption. Each sorption is followed by a desorption step. In a given length of time different species of molecules spend varying periods of time on the adsorbent and in the solution thus separating one species of molecules from the other. While going through this interchange the velocity of the molecule is decreased compared with the flow velocity of the mobile phase. The ratio of solute velocity to the liquid velocity is referred to as the $R_{f}$ value (Giddings, 1965; Snyder, 1968). The value ranges from zero to one.

Given a sufficient period of time, adsorption approaches a state of dynamic equilibrium. If we confine a specific adsorbent and a solution of a given compound under study for long enough time, the system will come to dynamic equilibrium and at that time the amount of solute retained per unit weight of adsorbent bears a relation with the amount of solute left in the 1iquid phase (Lederer and Lederer, 1957; Talbert and Fletcha11, 1965; Liu et a1., 1970; Green et a1., 1968; Weber et a1., 1965). This relation is usually linear for dilute solutions. It is generally written as

$$
\mathrm{C}_{\mathrm{S}}=\mathrm{K} \mathrm{C}_{1} \ldots
$$

where $C_{1}=$ concentration of solute in the liquid phase, $\mu \mathrm{g} / \mathrm{ml}$

$C_{S}=$ amount of solute retained in the solid phase on the adsorbent, $\mu \mathrm{g} / \mathrm{gm}$

$\mathrm{K}=$ proportionality constant (distribution coefficient or partition coefficient, $\mathrm{m} 1 / \mathrm{gm}$ 
The distribution coefficient $\mathrm{K}$ has been used for predicting the movement of organic chemicals and herbicides in soils by Davidson et al. (1968), Davidson and Santelman (1968), Oddson et a1. (1970), and Rhee and Amundson (1970).

At high solute concentrations, the equilibrium relationship between the solution and the adsorbed phase will not be linear. Attempts have been made by Giddings (1965), Snyder (1968), and Rhee and Amundson (1970) to predict movement for non linear adsorption. The discussion here will be restricted to linear cases.

The value of $\mathrm{K}$ can be experimentally determined by taking a known amount of soil in a suitable container and adding a predetermined volume of solution with known concentration (Liu et a1., 1970 and Talbert and Fletcha11, 1965). To test the linearity between solution and adsorbed phases the solutions with several different concentrations are allowed to come to equilibrium with the soil. The so-called "adsorption isotherms" are obtained by statistically fitting a straight line for the experimental points. The equation used for experimental determination of $\mathrm{K}$ is:

$$
\mathrm{K}=\frac{\mathrm{C}_{\mathrm{O}}-\mathrm{C}_{1}}{\mathrm{C}_{1}} \cdot \frac{\mathrm{V}}{\mathrm{W}}=\frac{\mathrm{C}_{\mathrm{S}}}{\mathrm{C}_{1}} \cdot \frac{\mathrm{V}}{\mathrm{W}}
$$

where $\mathrm{K}$ - distribution coefficient; also called partition

$$
\begin{aligned}
& \text { coefficient, } \mathrm{ml} / \mathrm{gm} \\
& \mathrm{C}_{0}=\text { amount of solute in solution before equilibrium, } \mu \mathrm{g} / \mathrm{ml} \\
& \mathrm{C}_{1}=\text { amount of solute in solution after equilibrium, } \mu \mathrm{g} / \mathrm{m} 1 \\
& \mathrm{C}_{0}-\mathrm{C}_{1}=\mathrm{C}_{\mathrm{s}}=\begin{array}{l}
\text { amount of solute retained on the soil after } \\
\text { equilibrium, } \mu \mathrm{g} / \mathrm{gm}
\end{array} \\
& \mathrm{V}=\text { volume of solvent, } \mathrm{m} 1 \\
& \mathrm{~W}=\text { weight of adsorbent, gm }
\end{aligned}
$$


Lederer and Lederer (1957) related the quantity $\mathrm{R}_{f}$ and the distribution coefficient by the following equation.

$$
\begin{array}{ll}
K=\frac{1-B_{f}}{R_{f}} & 2.8
\end{array}
$$

\section{Mathematical Models}

Transport phenomens in soil did not receive much attention until the early 1900's. After Buckingham (1904) gave a detailed treatment to the study of soils, the subject has attracted a great deal of attention of scientists from the disciplines of physics, chemistry, and biology. With more understanding of the subject, the problems are becoming more specific. Because complex phenomena are not easily visualized in their full perspective, scientists have invariably attempted to explore or understand them through simplified mathematical models and hypotheses. This technique had provided limited understanding of otherwise impossible situations. Through simplified models it is possible to understand the nature of the atom. It is beyond the scope of this dissertation to cite all the cases that have been solved with the help of models. I shall therefore discuss briefly a few of the successful models in describing the transport of matter through soils.

\section{Thermodynamic Model}

Methods of thermodynamics are applicable to systems of a well defined geometrical volume of macroscopic dimensions. Thermodynamic systems are classified according to the exchange of energy and matter through their boundaries (Prigogine, 1965). There are mainly three classes; a) isolated systems which can exchange neither energy nor matter, b) closed systems which exchange energy (heat and work) but not matter, and c) open systems 
which exchange both energy and matter with the exterior. Open systems are of great importance for biological and physical thermodynamics.

of particular importance to transport mechanisms in the soil is the work of Onsager (1931) where he arrived at reciprocal relations in irreversible processes based on statistical probability. Irreversible thermodynamics was used by Taylor and Cary (1960) to investigate simultaneous movement of water and heat in soil systems. Later the flow of matter and energy were studied by Taylor and Cary (1964). In light of these studies, linear rate equations were derived by Abdelaziz and Taylor (1965) to describe simultaneous movement of solutes and water; Yang (1966) used these equations to describe the movement of herbicides and water in unsaturated soils. Freed et a1. (1962) suggested an equation for predicting the depth to which the band of surface-applied herbicide will travel based upon the enthalpy of adsorption. Thermodynamic models usually require a dynamic equilibrium state; their applications are quite limited since actual field conditions are seldom at equilibrium.

Capillary Tube Mode1

Studies on the movement of solutes and dyes in porous media have been reported by Taylor (1953). He has analytically investigated the spreading of substances in capillaries due to the combined action of molecular diffusion and the variation of microscopic velocity over the cross section. He also observed that distribution of solute concentration in the capillaries was centered around a point which moves with the mean speed of liquid flow and was symmetrical about that point. Philip (1963a and 1963b) analyzed dispersal or mixing of solutes during laminar flow in straight tubes considering molecular diffusion and convection in a fluid subject to steady Poiseuille flow. These fundamental investigations apply very appropriately for clean glass tubes of uniform diameter. Glass acts 
purely as a non-reactive and non-adsorbent pore wall. For soil material capillaries are neither straight and uniform, nor is the soll an inert medium. Therefore, the general application of the capillary model has not been made in the movement of solutes.

\section{Chromatographic Mode1}

Martin and Synge (1941) considered that development of a chromatogram to be closely analogous in its mode of operation to distillation and extraction fractionating columns and developed the theory of chromatography. They proposed the concept of 'theoretical plates'. From that beginning, the theory of chromatography has developed into a very refined technique in studying movement of chemical in adsorbent beds for chemical engineers and civil engineers. Application of these concepts to problems in soil science started with Day (1956) during a study of salt water displacing fresh water in water-saturated sand beds. Dispersion of salt at the boundary between the two liquid phases was greater than could be expected from purely ion diffusion. He attributed this to a mechanism which he referred to as hydrodynamic dispersion. He proposed a mathematical model based upon a statistical theory developed by Scheidegger (1954). Another theoretical analysis was made by Lapidus and Amundson (1952) dealing with longitudinal diffusion and convection in ion exchange and chromatographic columns. The displacement nature of the liquids in a porous column is dependent upon: a) molecular diffusion, b) convective force, and c) a range of microscopic flow velocities in the column cross section. Total dispersion was treated as one parameter in elution curves by Nielsen and Biggar (1961), Brenner (1962), Hashimoto et al. (1964), and Nielsen and Biggar (1963). From the theory developed by these workers, the application to the movement of nutrients are reported by Miller et a1. (1965), Saddler(1965), Kay and Elrick 
(1967), Corey (1966). An attempt to describe pore structure of soils by miscible displacement technique has been made by Corey et al. (1963).

The displacement of gases in soils has been reported by Rolston et al. (1969) as a miscible displacement process.

Herbicide movement in soil as a miscible displacement has been studied by Davidson et a1. (1968), Davidson and Santelman (1968), Kay and Elrick (1967), Lindstrom et a1. (1967) and Green et a1. (1968). The genera1 one-dimensional transport equation used by these workers is:

$$
\begin{array}{lll}
\frac{\partial C}{\partial t}=D \frac{\partial^{2} C}{\partial x^{2}}-v \frac{\partial C}{\partial x}-\frac{d s}{d t} & 2.9
\end{array}
$$

where $\mathrm{C}=$ concentration, gm/1.

$D=$ diffusion coefficient, $\mathrm{cm}^{2} / \mathrm{sec}$.

$\mathrm{v}=$ velocity of fluid in the column, $\mathrm{cm} / \mathrm{sec}$.

$\mathbf{s}=$ quantity adsorbed on the soil surface, gm/gm.

$x=$ direction of fluid flow.

Assuming linearity between C and S, Davidson et a1. (1968) modified equation 2.9 to give

$$
\begin{array}{lll}
\left(1+\frac{P K}{\theta}\right) & \frac{\partial C}{\partial t}=D \frac{\partial^{2} C}{\partial x^{2}}-v \frac{\partial c}{\partial x}=0 & 2.10
\end{array}
$$

where $P=$ bulk density of soil, $\mathrm{gm} / \mathrm{cm}^{3}$

$$
\begin{aligned}
& K=\text { distribution coefficient, } \mathrm{cm}^{3} / \mathrm{gm} \\
& \theta=\text { volumetric water content, } \mathrm{cm}^{3} / \mathrm{cm}^{3}
\end{aligned}
$$

The solutions to equation 2.10 are obtained through the method of Laplace transforms by Davidson et a1. (1968) and Lindstrom et a1. (1967). During these studies the velocity is held at a very slow rate and thus the effects of diffusion cannot be neglected. 
In a normal soil, the liquid velocity is usually higher and the effects of diffusion may be considered negligible. Oddson et al. (1970) considered only the flow velocity and the adsorption terms, dropping the diffusion term and gave their second order differential equation describing the concentration of adsorbed chemical on soil as:

$v \frac{\partial^{2} s}{\partial x \partial t}+\frac{\partial^{2} s}{\partial t^{2}}+\alpha v \frac{\partial s}{\partial x}+\alpha(k+1) \frac{\partial s}{\partial t}=0$

where $S=$ concentration of adsorbed chemical per unit volume of media, $\mathrm{gm} / \mathrm{cm}^{3}$

$\alpha \& \mathrm{~K}=$ are constants.

Rhee et al. (1970) proposed the following first order differential equations for a multicomponent system with negligible diffusion.

$\frac{\partial}{\partial x}\left(c_{i}-\mu s_{i}\right)+\frac{\partial}{\partial t}\left(c_{i}-\nu s_{i}\right)=0$

where $C_{i}=$ concentration in fluid phase of $i^{\text {th }}$ component, moles $/ \mathrm{cm}^{3}$

$S_{i}=$ concentration in solid phase of $i^{\text {th }}$ component, moles $/ \mathrm{cm}^{3}$

$\nu=$ volumetric flow rate ratio

$\mathrm{v}=$ volume ratio

Equations 2.11 and 2.12 seem to hold good under certain conditions for solute transport in soil. All these studies made so far using chromatographic models are conducted under conditions of water-saturation. By their adaptability, the chromatographic models are very versatile and have been very promising.

On the basis of the model by Rhee et al. (1970), I have proposed in Chapter IV of this dissertation a model to describe solute transport during water infiltration through initially dry soil. 


\section{THEORETICAL}

Consider a column of cross sectional area A and length L filled with dry soil oriented along the $z$ - axis. Within the column, the mobile phase with solute concentration $C_{1}$ is introduced from the bottom with a constant flux $Q$ maintained at all times thereafter. The mobile phase moves through the stationary phase and, while doing so, exchanges the molecules of the solute through adsorption. Thus, we introduce the assumption that the concentration (activity) of solute in the liquid phase $C_{1}$, and in the solid phase $C_{s}$ tends to be at equilibrium. It was found in a study by Weber et al., 1965, that 2,4-D did not attain equilibrium even after 48 hours at $10^{\circ} \mathrm{C}$ on an anion exchanger. It took 6 hours to come to equilibrium at $55^{\circ} \mathrm{C}$. This suggests that there is no instantaneous equilibrium. For the case of dilute solutions, at equilibrium there exists a linear relation between $C_{1}$ and $C_{s}$ :

$$
\mathrm{C}_{1}=\mathrm{m} \mathrm{C}_{\mathrm{s}} \quad 3.1
$$

where $\mathrm{m}$ is a constant

The transfer of solute from the liquid to solid phase to attain equilibrium and vice versa is not instantaneous, but is dependent on what we call the "transfer coefficient, $k$ (dimensions $L / T$ )." The idea of this coefficient is used by Oddson et a1., 1970 and Rhee and Amundson, 1970. It is analogous to resistance to the transfer of solute from the liquid to solid phase and also from the solid to liquid phase. 
Let us consider a thin plate of thickness dz at a distance $z$ in the column.

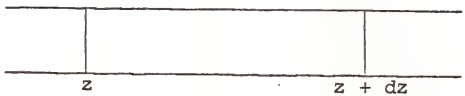

Let $Q=$ volume rate of fluid phase $\frac{\mathrm{L}^{3}}{\mathrm{~T}}$

$c_{1}=$ solute concentration in the fluid phase $\frac{M}{L^{3}}$

$C_{S}=$ solute concentration in solid phase $\frac{M}{L^{3}}$

$A=$ cross sectional area $L^{2}$

$E=$ porosity

$\mathrm{m}=$ proportionality constant

$a=$ surface area/unit volume. $\frac{1}{\mathrm{~L}}$

$k=\operatorname{transfer}$ coefficient $\frac{\mathrm{L}}{\mathrm{T}}$

The net accumulation of solute in the column between

$z$ and $z+d z$ in the liquid phase is represented as:

$$
\begin{gathered}
Q C_{1}\left|-Q C_{1}\right|-A d z \text { ka }\left(C_{1}-m C_{s}\right)= \\
z z+d z \\
E A d z \frac{\partial C_{1}}{\partial t}
\end{gathered}
$$

eqn 3.2 becomes

$-Q \frac{\partial C_{1}}{\partial z}-\mathrm{Ak}$ a $\left(C_{1}-\mathrm{mC}_{\mathrm{s}}\right)=\mathrm{EA} \frac{\partial \mathrm{C}_{1}}{\partial t}$

or

$\mathrm{Q} \frac{\partial \mathrm{c}_{1}}{\partial \mathrm{z}}+\mathrm{EA} \frac{\partial \mathrm{c}_{1}}{\partial \mathrm{t}} \mathrm{Ak} \mathrm{a}\left(\mathrm{c}_{1}-\mathrm{mc}_{\mathrm{s}}\right)=0$

Dividing 3.4 by $\mathrm{A}$ results in

$\mathrm{v} \frac{\partial \mathrm{c}_{1}}{\partial z}+\mathrm{E} \frac{\partial \mathrm{c}_{1}}{\partial t}+\mathrm{k} \mathrm{a}\left(\mathrm{c}_{1}-\mathrm{mc}_{\mathrm{s}}\right)=0$

where $\mathrm{V}=$ velocity $\left(\frac{\mathrm{L}}{\mathrm{T}}\right)$ 
On the same argument the solute concentration on the solid phase could be described as:

$$
(1-E) \frac{\partial C_{s}}{\partial t}-k \text { a }\left(C_{1}-m C_{s}\right)=0
$$

Boundary conditions are

$$
\begin{aligned}
& C_{1}(z, 0)=0 \\
& C_{s}(z, 0)=0 \\
& C(0, t)=C_{0}(t)
\end{aligned}
$$

Thus, we now have two linear first order differential equations (3.5 and 3.6), for two unknown variables $C_{1}$ and $C_{s}$. Solution for $C_{1}$ is obtained by taking Laplace transforms of 3.5 and 3.6 and then solving the transformed equations simultaneously as below:

Laplace transform of 3.5 is:

$$
\mathrm{v} \frac{\partial \hat{\mathrm{C}}_{1}}{\partial z}+\mathrm{S} E \hat{\mathrm{C}}_{1}+\mathrm{k} a\left(\hat{\mathrm{C}}_{1}-\mathrm{m} \hat{\mathrm{C}}_{\mathrm{s}}\right)=0
$$

where $\hat{C}$ denotes $C$ in laplace space. Similarly the transformed 3.6 is

$$
S(I-E) \hat{C}_{S}-k a\left(\hat{C}_{I}-m \hat{C}_{S}\right)=0 \text {. }
$$

In equation $3.8, \hat{C}_{s}$ is solved in terms of $\hat{C}_{1}$ as

$$
\hat{C}_{S}=\frac{\hat{C}_{1} k a}{S-S E+k a m}
$$

upon substitution of the above solution of $\hat{C}_{S}$ in equation 3.7 we get

$$
v \frac{\partial \hat{C}_{1}}{\partial z}+s E \hat{C}_{1}+k a \hat{C}_{1}-\frac{k^{2} a^{2} m \hat{C}_{1}}{s-s E+k a m}
$$

Collecting coefficients it becomes

$$
\mathrm{V} \frac{\partial \hat{\mathrm{C}}_{1}}{\partial z}+\hat{\mathrm{C}}_{1}\left[\mathrm{E} \mathrm{S}+\mathrm{k} \mathrm{a}-\frac{\mathrm{k}^{2} \mathrm{a}^{2} \mathrm{~m}}{\mathrm{~S}(\mathrm{l}-\mathrm{E})+\mathrm{k} \mathrm{a}}\right]=0
$$


or

$$
\frac{\partial \hat{C}_{1}}{\hat{C}_{1}}=-\frac{1}{V}\left[E S+k a-\frac{k^{2} a^{2} m}{s(1-E)+k a m}\right]
$$

integration of 3.12 gives

$\ln \hat{c}_{1}=-\frac{z}{V}\left[E s+k a-\frac{k^{2} a^{2} m}{s(1-E)+k a m}\right]$

$\hat{c}_{1}(z, S)=\exp \left[-\frac{z}{V} E S\right] \cdot \exp \left[-\frac{z}{V} k a\right]$.

$\exp \left[\frac{z}{V}\left(\frac{k^{2} a^{2} m}{S(1-E)+k a m}\right)\right] \cdot \quad \hat{c}_{0}$

$\therefore \hat{c}_{1}(z, t)=\exp \left[-E \frac{z}{v} s\right] . \quad \exp \left[-\frac{z}{v} k a \frac{s}{s+\frac{m k a}{l-E}}\right]$

. $\hat{\mathrm{C}}_{0}$ (S)

Let $\theta=\frac{E L A}{Q}=\frac{E L}{V}$ (Time)

now 3.15 becomes

$$
\hat{c}_{1}(z, s)=\exp \left[-\theta \frac{z}{L} s\right] \cdot \exp \left[-\theta \frac{z}{L} \frac{k a}{E} \frac{s}{s+\frac{m E}{l-E} \frac{k a}{E}}\right] \cdot \hat{c}_{0}(S) \text {. }
$$

Let $K=\frac{k a}{E}$ (time ${ }^{-1}$ ) and $\mu=\frac{m E}{1-E}$. Now in terms of $\theta, K$, $\mu$, the equation 3.16 is:

$\hat{C}_{1}(z, S)=\exp \left[-\theta \frac{z}{L} s\right] \cdot \exp \left[-\theta \frac{z}{L} K \frac{S}{S+\mu K}\right] \cdot \hat{C}_{0}(S)$

Again with the substitution $\frac{\mathrm{Z}}{\mathrm{L}}=\varnothing 3.17$ becomes

$\hat{C}_{1}(z, S)=\exp [-\phi S] \exp \left[-\phi K \frac{S}{S+\mu K}\right] \cdot \hat{C}_{0}(S)$

or $\hat{C}_{1}(z, S)=\exp [-\phi s] \cdot \exp \left[-\phi K\left(1-\frac{\mu K}{S+\mu K}\right)\right] \cdot \hat{C}_{0}(S)$

3.19

or

$\hat{C}_{I}(z, s)=\exp [-\phi S] \cdot \exp [-\phi K] \cdot \exp \left[\phi \mu K^{2} \frac{1}{S+\mu K}\right] \cdot \hat{C}_{0}(S)$ 
Dividing and multiplying 3.20 by $(S+\mu K)$ yields

$$
\begin{aligned}
& \hat{C}_{1}(z, S)=\exp [-\phi S] \exp [-\phi K] \frac{1}{S+\mu K} \cdot\left[\exp \phi \mu K^{2} \frac{1}{S+\mu K}\right] \cdot \\
& (S+\mu K) \hat{C}_{0}(S)
\end{aligned}
$$

The inverse transform of 3.21 gives

$$
\begin{aligned}
& C_{1}(z, t)=\exp (-\phi K) \int_{0}^{t-\phi} \exp (-\mu K \tau) I_{0}\left(2 \sqrt{\phi \mu K^{2}}\right) . \\
& {\left[c_{0}^{\prime}(t-\phi-\tau)+\mu K C_{0}(t-\phi-\tau)\right] d \tau}
\end{aligned}
$$

where $I_{0}(x)$ is modified Bessel function of $0^{\text {th }}$ order.

The above solution is expanded to account for the delta function $C_{0}^{\prime}(t-\phi-\tau)$ and step function $\mu K C_{0}(t-\phi-\tau)$ according to the input conditions. Solution is divided into two parts: $U_{1}$ and $U_{2}$ so that the sum of both gives $c(z, t)$.

$$
\begin{aligned}
& U_{1}=\left\{\begin{array}{l}
0 \text { for } t-\phi \leq 0 \\
c^{0} \mu \mathrm{K} \exp (-\phi K) \int_{0}^{t-\phi} \exp (-\mu \mathrm{K} \tau) \cdot I_{0}\left(2 \sqrt{\phi \mu K^{2} \tau}\right) d \tau \\
\text { for } 0<t-\phi<T \text { and } \\
C^{0} \mu \mathrm{K} \exp (-\phi K) \int_{t-\phi-\tau}^{t-\phi} \exp (-\mu \mathrm{K} \tau) \cdot I_{0}\left(2 \sqrt{\phi \mu \mathrm{K}^{2} \tau}\right) d \tau \\
\text { for } t-\phi>T
\end{array}\right. \\
& U_{2}=\left\{\begin{array}{l}
0 \text { for } t-\phi \leq 0 \text { and } \\
C^{0} \exp (-\phi K) \exp [-\mu \mathrm{K}(t-\phi)] \cdot I_{0}\left(2 \sqrt{\phi \mu \mathrm{K}^{2}(t-\phi}\right) \\
\text { for } 0<t-\phi<\mathrm{T} \text { and } \\
\mathrm{C}^{0} \exp (-\phi \mathrm{K}) \cdot \exp [-\mu \mathrm{K}(\mathrm{t}-\phi)] \cdot\left[\mathrm{I}_{0}\left(2 \sqrt{\phi \mu \mathrm{K}^{2}(t-\phi)}\right)\right. \\
\left.-\exp (-\mu \mathrm{K} \mathrm{T}) \cdot \mathrm{I}_{0}\left(2 \sqrt{\phi \mu \mathrm{K}^{2}(t-\phi-T)}\right)\right]_{\text {for }} t-\phi>\mathrm{T}
\end{array}\right.
\end{aligned}
$$


Where $\mathrm{T}$ is the length of time the slug was applied.

Now the $\mathrm{C} / \mathrm{C}^{0}$ is obtained as:

$$
\frac{c}{c^{0}}=\frac{U_{1}+U_{2}}{c^{0}}
$$

The solution derived here is similar to the solution of Oddson et al., 1970, for their special case where the soil did not have any chemical origina11y.

In the Results and Discussion section, the experimental results have been compared against the theoretical curves, computed on an IBM 360 system using Fortran IV language (G). The program is given in the Appendix. 


\section{EXPERIMENTAL}

\section{Introduction}

The theory developed in the previous section was experimentally tested by displacing 2,4-D herbicide on four soil materials varying considerably in their physical properties.

The air dry soils were packed into lucite columns which were held vertical during the experiments. Herbicide $(2,4-D)$ solution with a concentration of $10 \mathrm{ppm}$ was introduced at a constant predetermined flux at the bottom of the column with a positive displacement pump. After a predetermined volume was pumped in, the herbicide solution was stopped and immediately pure water was started with the same flux; thus the water displaced the herbicide solution plug through the rest of the soil column and out of it. Small samples (25 microliter) of soil solution were extracted periodically at the $15 \mathrm{~cm}$ mark and the effluent from the other end was collected in fractions of $5 \mathrm{ml}$ each. The extract and the effluent samples were analyzed for 2,4-D content and plotted. Theoretical curves were compared against the experimental results.

\section{Soils}

The soils used in the studies were Lakeland fine sand, Fellowship subsoil (sandy clay), Everglades mucky peat and glass beads (105-210 $\mu$ ) supplied by Microbeads Division (Cataphote Corporation), Jackson, Mississippi. Details of locality and depth of collection of soil samples are shown in Table 1. 
Table 1. Description of locality and the depth from which soil samples were collected.

\begin{tabular}{|c|c|c|}
\hline $\begin{array}{c}\text { Name of } \\
\text { soil }\end{array}$ & Locality & $\begin{array}{l}\text { Depth } \\
\mathrm{cm}\end{array}$ \\
\hline $\begin{array}{l}\text { Lakeland } \\
\text { fine sand }\end{array}$ & $\begin{array}{l}\mathrm{SE}_{\frac{1}{4}} \mathrm{NE} \frac{1}{4} \mathrm{Sec} .2, \mathrm{~T} \text { loS } \\
\mathrm{R} 2 \mathrm{OE} \text {, Alachua County }\end{array}$ & $2.5-23.0$ \\
\hline $\begin{array}{l}\text { Fellowship } \\
\text { subsoil }\end{array}$ & $\begin{array}{l}\mathrm{SE}_{\frac{1}{4}} \mathrm{NW} \frac{1}{4} \text { Sec. } 17, \mathrm{~T} \text { los } \\
\mathrm{R} 2 \mathrm{OE} \text {, Alachua County }\end{array}$ & $30.0-50.0$ \\
\hline $\begin{array}{l}\text { Everglades } \\
\text { micky peat }\end{array}$ & $\begin{array}{l}\mathrm{NE} \frac{1}{4} \mathrm{NE} \frac{1}{4} \mathrm{Sec} .33, \mathrm{~T} 2 \mathrm{OS} \\
\mathrm{R} 27 \mathrm{E} \text {, Orange County }\end{array}$ & $0.0-30.0$ \\
\hline
\end{tabular}


Samples of Lakeland fine sand and Fellowship subsoil were air dried and passed through a $2 \mathrm{~mm}$ sieve after collection. Mucky peat was stored in polyethylene bags at the time of collecting and was kept air tight for the purpose of preventing water loss. This precaution was taken because this soil becomes water repellent when dry. The sample was, however, passed through a $2 \mathrm{~mm}$ sieve and stored in a polyethylene bag in the laboratory. Some physical properties of the soils are given in Results and Discussion.

The packing procedure consisted of pouring approximately 50 to 75 $\mathrm{cm}^{3}$ loose soil into the soil cylinder, stirring thoroughly with a lucite rod and tapping slightly around the outside of the cylinder with the palm of the hand. Care was taken to minimize stratification within the column. A rubber septum with a custom constructed liquid sample collecting device was installed at $15 \mathrm{~cm}$ from the bottom of the column during packing.

\section{Physical Set-up of Flow System}

All soil columns used in the experiments were contained in a lucite plastic cylinder $7.6 \mathrm{~cm}$ inside diameter and $30 \mathrm{~cm}$ long. The cylinder was supported between custom made plastic end-plates by means of four bolts and wing nuts. Fritted plastic porous discs (medium porosity) were used in both end-plates such that the fritted discs were firmly in contact with the soil. There was a very small liquid reservoir behind each porous disc so that the volume was negligible under rapid flow conditions (Fig. 1). Total volume of both reservoirs was $16 \mathrm{ml}$. The soil columns were held vertical during the experiment in a constant temperature chamber at $24^{\circ} \mathrm{C} \pm 1^{\circ} \mathrm{C}$. The constant temperature chamber and fraction collector was purchased as a unit from Gilson Medical Electronics, Inc., 3000 West Beltline Highway, Middleton, Wisconsin. 


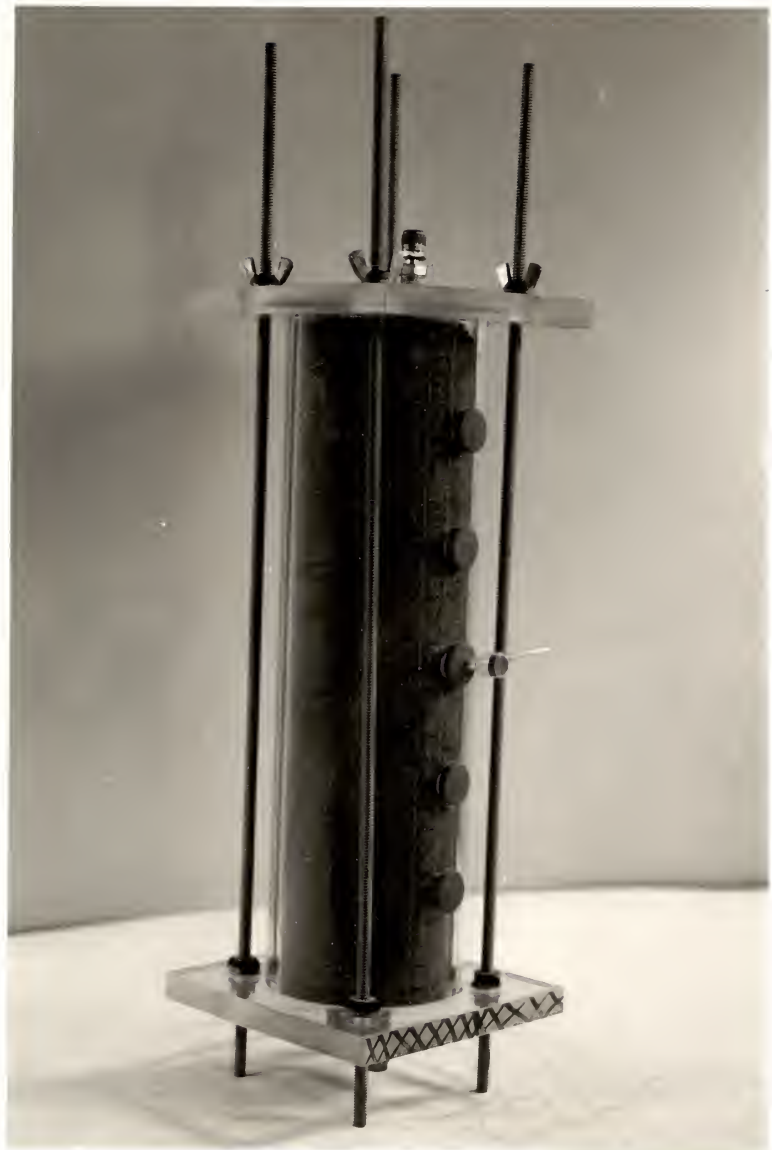

Figure 1. The general set-up of soil column during the displacement studies. 
Two inlet ports were provided for introducing 2,4-D herbicide solution and water directly at the reservoir behind the porous disc. Each port was connected to one positive displacement pump by means of $2 \mathrm{~mm}$ I.D. nylon tubing. The pair of pumps were electronically actuated to switch operations from one to the other. The pump unit was a model 190 Dialagrad programmed gradient pump. It was bought from Instrumentation Specialties Company, Inc., 5624 Seward Avenue, Lincoln, Nebraska. At the start of the experiment, pump "A" was turned on at time 0 . The herbicide solution was pumped into the soil column from the bottom at constant volume rate so the flow was vertically upwards. During this time, the air from within the voids was free to escape through the top ports. At time ' $\mathrm{T}$ ' (200 ml solution) the flow system was switched to pump 'B'. Now the herbicide-free water entered the column at the same rate, displacing the herbicide solution along the soil column. Flow rates were 50 and 100 $\mathrm{cm}^{3} / \mathrm{h}$ so that the velocities across the cross section $\left(45.4 \mathrm{~cm}^{2}\right)$ were 1.1 and $2.2 \mathrm{~cm} / \mathrm{h}$. In each run $200 \mathrm{ml}$ of $10 \mathrm{ppm}$ solution of 2,4-D was introduced. The displacing water had 0.5 percent of phenol added to prevent possible microbia1 breakdown of 2,4-D.

At $15 \mathrm{~cm}$ from the column bottom, the sampling device was operated to extract small amounts of liquid samples under an applied suction of $100 \mathrm{~cm}$ of water. The sampling system consisted of a small medium porosity ceranic plate in contact with the soil and a septum to facilitate drawing the samples with a hypodermic needle (Fig. 2). The porous plate of the device was about $2 \mathrm{~cm}$ away from the inside wall and was $9 \mathrm{~mm}$ in diameter. A small reservoir behind the porous plate was helpful in retaining soil solution at the time of collecting sample by means of a hypodermic needle. Samples (25 microliter) were collected every 10 minutes for analysis of 


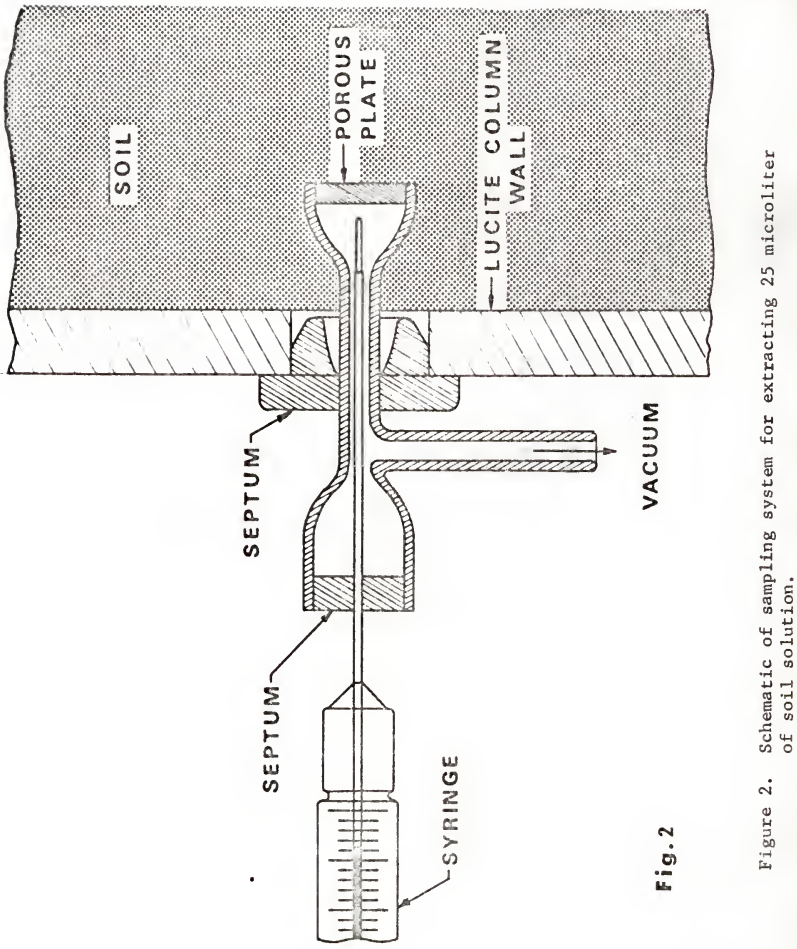


2,4-D. Suction was applied just prior to collecting the samples and immediately afterwards the suction lime was clamped off. This procedure was followed to prevent disturbance of the soil flow system which might have occurred with constant draining.

Liquid effluent from the top of the column was collected in volumetric fractions of $5 \mathrm{ml}$ with an automatic fraction collector built in the constant temperature chamber.

\section{Preparation and Analysis of Herbicide Solution}

The ${ }^{14} \mathrm{C}$ labeled $2,4-\mathrm{D}$ herbicide was used throughout this study for displacement and adsorption experiments. Radioactive chemical was purchased from Mallinckrodt Chemical Works, St. Louis, Missouri. The manufacturer specified that the chemical had a specific radioactivity of $3.03 \mathrm{mCi} / \mathrm{mM}$, so $21.9 \mathrm{mg}$ of chemical had $0.3 \mathrm{mCi}$. A whole capsule containing $21.9 \mathrm{mg}$ was emptied into 2.19 liters of distilled water to give a concentration of $10 \mathrm{ppm}$. The mixture was stirred thoroughly and stored in a refrigerator at $7^{\circ} \mathrm{C}$.

Analysis for 2,4-D in aqueous solutions was performed by liquid scintillation counting with a Packard Model 314 EX TRI-CARB series spectrometer with bi-alkali photomultiplier tubes. The unit was purchased from Packard Instrument Company, Box 428, LaGrange, Illinois. Counting efficiency for ${ }^{14} \mathrm{C}$ was $58 \%$ using a dioxane base scintillation cocktail mixture with spectrometer settings of 280 for the lower discriminator, 1000 for the upper discriminator, $7 \%$ gain and 900 volts.

A scintillation cocktail slightly modified from the formula given by Bray (1960) was used. Details of this cocktail are presented in Table 2 . 
Table 2. Scintillation mixture for counting radioactivity in aqueous samples.

Compound

Quantity

PPO ( 2,5-diphenyloxazole)

$4.0 \mathrm{gm}$

POPOP ( 2,2 -p-phenylenebis (5-phenyloxazole)

$0.2 \mathrm{gm}$

Naphthalene

$60.0 \mathrm{gm}$

Methanol

$100.0 \mathrm{ml}$

Ethylene Glycol

$20.1 \mathrm{ml}$

P-Dioxane

$880.0 \mathrm{ml}$

Concentration of 2,4-D herbicide in effluent was determined by radio assay of ${ }^{14} \mathrm{C}$ on the carboxyl radical. One $\mathrm{ml}$ of each aqueous sample containing radioactive carbon was measured into a glass scintillation vial containing $15 \mathrm{ml}$ of Bray's mixture, stirred, and allowed to cool in the refrigerator of the scintillation spectrometer for about 2 hours prior to counting. In the case of 25 microliter samples of extract, all of the quantity was used in $15 \mathrm{ml}$ of scintillation mixture. Each sample was counted for 10 minutes to reduce statistical counting error and the corresponding background counts were substracted to give the ${ }^{14} \mathrm{C}$ count due to the presence of $2,4-D$. The ratio of counts in the effluent (C) to those in the stock solution $\left(\mathrm{C}^{\circ}\right)$ was used in the elution curves ( $\mathrm{plot}$ of $\mathrm{C} / \mathrm{C}^{\circ}$ versus time or accumulative influent volume). Displacement runs were replicated 3 times.

The C atom on the carboxyl group of 2,4-D molecule was labeled in the sample used, additional analyses were conducted. Thin layer chromato- 
graphic analyses for 2,4-D in the effluent samples were therefore made to detect possible microbial and/or chemical breakdown of 2,4-D in the soil columns during displacement. Here a streak of radioactivity distribution on the chromatogram or zones (blobs) should indicate degradation products. A few effluent samples were selected at random for these analyses. About $1 / 2 \mathrm{ml}$ of aqueous sample was placed in a $1 / 2 \mathrm{ml}$ centrifuge tube. The volume was reduced to approximately 15 to 20 microliters under a steady stream of nitrogen gas. The concentrated sample was drawn into a fine capillary tube by dipping the capillary tube into the liquid. All the liquid in the capillary tube was spotted on a TLC (thin layer chromatographic) plate. Spotting was done at an interval of $1 \mathrm{~cm}$ between the spots on a straight line $2.5 \mathrm{~cm}$ from the bottom of the TLC plate. All precautions were taken to see that the spots were as small as possible by depositing very little solution on the spot at a time and allowing it to dry before depositing the remainder from the capillary tube. The TLC plates were precoated aluminum oxide type GF on glass sheet of size $20 \mathrm{x} 20 \mathrm{~cm}$ with coating thickness of $250 \mu$. The TLC plate thus spotted was dried and placed in a glass trough containing the developing solvent. The solvent used for development of a chromatogram of 2,4-D was a mixture of isopropyl alcohol, ammonium hydroxide and water at a ratio of $8: 1: 1$ by volume, respectively. The plate was removed from the bath when the wetting front of the solution reached $10 \mathrm{~cm}$ height from the original spots and then dried by evaporation under a hood. Radioactivity distribution on the chromatogram was determined by autoradiograph on $\mathrm{x}$-ray film. The dried plate was placed in contact with Kodak no-screen $x-r a y$ film and allowed an exposure of 72 hours in the darkroom. The x-ray film was later developed with $x$-ray film developer and fixer. 


\section{Adsorption Isotherms}

Adsorption of 2,4-D herbicide on all four soil materials was studied at the equilibrium state. Five grams of soil (air-dry) were weighed into $50 \mathrm{ml}$ capacity polypropylene plastic tubes of $29 \mathrm{~mm}$ diameter and $104 \mathrm{~mm}$ length. Stock solutions of radioactive 2,4-D were made from the main stock solution described previously to give $10,8,6,4$, and 2 ppm concentrations. From each concentration including zero, $25 \mathrm{ml}$ of solution was added to each tube. Soil and the 2,4-D solution were allowed to come to equilibrium by shaking them in a reciprocating shaker for 8 hours at $24^{\circ} \mathrm{C} \pm 1^{\circ} \mathrm{C}$. Samples were then centrifuged at $15,000 \mathrm{rpm}$ per 15 minutes in a Sorval1 superspeed centrifuge SS-3 (Ivan Sorva11, Inc., Norwa1k, Conn). One $\mathrm{ml}$ of supernatent liquid was pipetted into scintillation vials containing $15 \mathrm{ml}$ of Bray's mixture and counted in the 1iquid scintillation spectrometer. Similar counting was done on the stock solutions. From scintillation counts, the adsorption isotherms were plotted to determine the parameter $m$ for each soil. Here $m$ is the reciprocal of slope of adsorption isotherms plotted on the volume basis. Concentration of 2, 4-D in $\mu \mathrm{g} / \mathrm{ml}$ of soil was plotted on the $\mathrm{y}$-axis.

$$
\begin{aligned}
& \text { Thus, slope }=\frac{1}{\mathrm{~m}}=\frac{\mathrm{C}^{\circ}-\mathrm{Cl}}{\mathrm{C}_{1}} \cdot \frac{\mathrm{V}_{1}}{\mathrm{~V}_{\mathrm{S}}} \\
& \text { Where } \mathrm{C}^{\circ}=\text { counts per minute in stock solution } \\
& \mathrm{C}_{1}=\text { counts per minute in supernatant 1iquid } \\
& \mathrm{V}_{1}=\text { volume of liquid } \\
& \mathrm{V}_{\mathrm{S}}=\text { volume of soil }
\end{aligned}
$$

The volume of soil was obtained by dividing the sample weight by the particle density. 


\section{RESULTS AND DISCUSSION}

\section{Introduction}

In this section, breakthrough curves of 2,4-D in four different soil materials have been presented and discussed. The extent of applicability of the theory developed in the earlier sections has also been discussed.

The soil materials used ranged from organic soil like Everglades mucky peat to mineral soils like fine sand and silt loam. Selected physical properties of the soils are presented in Table 3 .

Additiona 1 analyses on random effluent samples were conducted by thin layer chromatography to check is there was any degradation of 2,4-D. Results of these analyses are presented in Figure 3 .

Results of adsorption isotherms on glass beads, Lakeland fine sand and Fellowship subsoil are presented in Figure 4, and those on Everglades mucky peat in Figure 5. Partition coefficients for all the materials are presented in Table 4 . All results are averages of three replications.

Breakthrough curves as determined at $15 \mathrm{~cm}$ and $30 \mathrm{~cm}$ distances and at $1.1 \mathrm{~cm} / \mathrm{h}$ and $2.2 \mathrm{~cm} / \mathrm{h}$ velocities for glass beads are presented in Figures 6, 7, 8, and 9; for Lakeland fine sand, Figures 10, 11, 12 and 13; for Fellowship subsoil, Figures 14, 15, 16 and 17; while for Everglades mucky peat, Figures 18, 19, 20 and 21.

Recovery of $2,4-D$ in the effluent was determined from the area under the breakthrough curves. Data for glass beads, Lakeland fine sand, Fellowship subsoil and Everglades mucky peat are presented in Tables 5, 
Table 3. Selected physical properties of soil materials and glass beads.

\begin{tabular}{|c|c|c|c|c|}
\hline & $\begin{array}{l}\text { Glass } \\
\text { beads }\end{array}$ & $\begin{array}{l}\text { Lakeland } \\
\text { fine sand }\end{array}$ & $\begin{array}{c}\text { Fellowship } \\
\text { subsoil }\end{array}$ & $\begin{array}{l}\text { Everglades } \\
\text { mucky peat }\end{array}$ \\
\hline$\%$ sand & - & 96.0 & 65.7 & - \\
\hline$\%$ silt & - & 3.3 & 6.7 & - \\
\hline$\%$ clay & - & 2.0 & 27.3 & - \\
\hline$\%$ organic matter & - & 0.73 & 2.97 & 74.55 \\
\hline CEC meq/100 gm & 0.68 & 3.96 & 27.83 & 79.70 \\
\hline$\%$ Water $^{1}$ & 0 & 2.66 & 5.23 & 43.70 \\
\hline Porosity & 0.360 & 0.330 & 0.448 & 0.433 \\
\hline $\begin{array}{l}\text { Bulk density } \\
\mathrm{g} / \mathrm{cm}^{3}\end{array}$ & 1.444 & 1.664 & 1.352 & 0.683 \\
\hline
\end{tabular}

*1 At the time of packing; on oven dry weight basis. 
Figure 3. Results of thin layer chromatograph analyses for 2, 4-D on selected effluent samples from glass beads, Lakeland fine sand, Fellowship subsoil and Everglades mucky peat. 


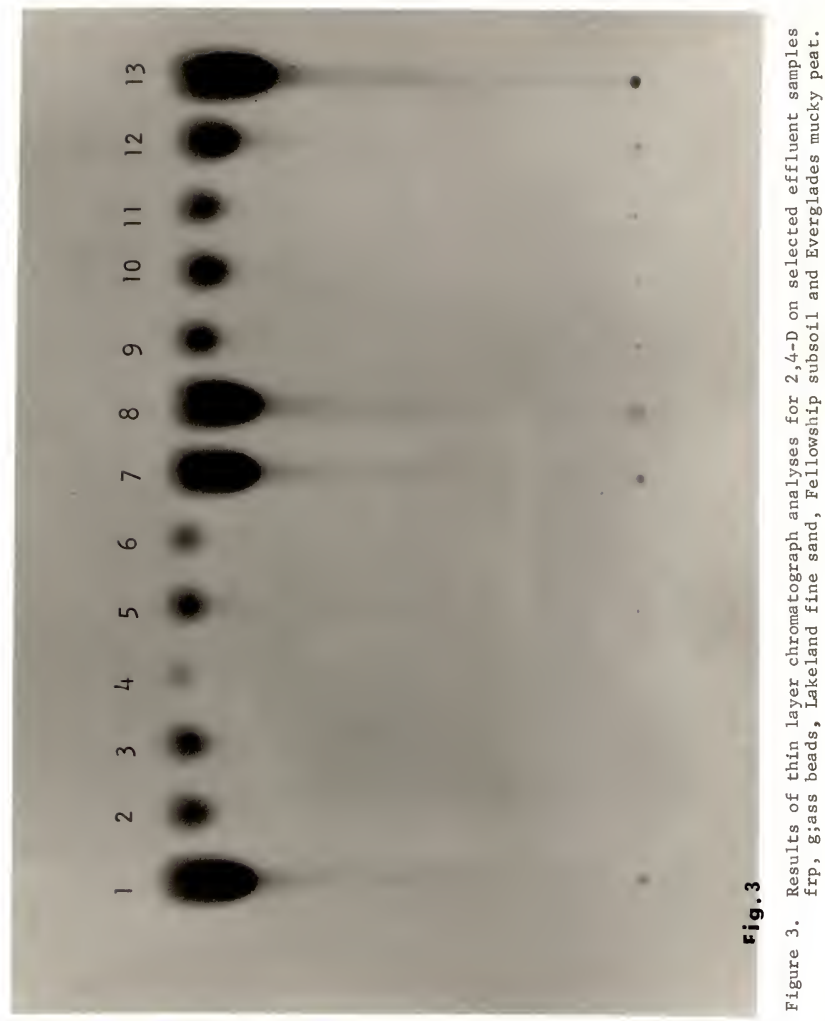


Figure 4. Adsorption of 2, 4-D herbicide on Fellowship subsoil, Lakeland sand and glass beads. 


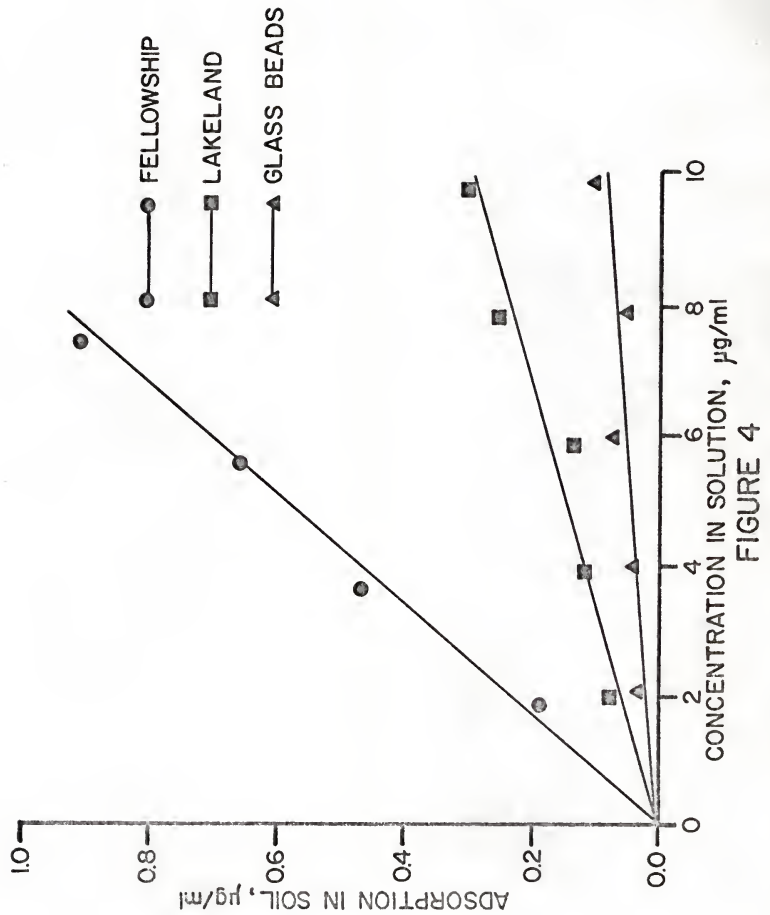


Figure 5. Adsorption of 2, 4-D herbicide on Everglades mucky peat. 


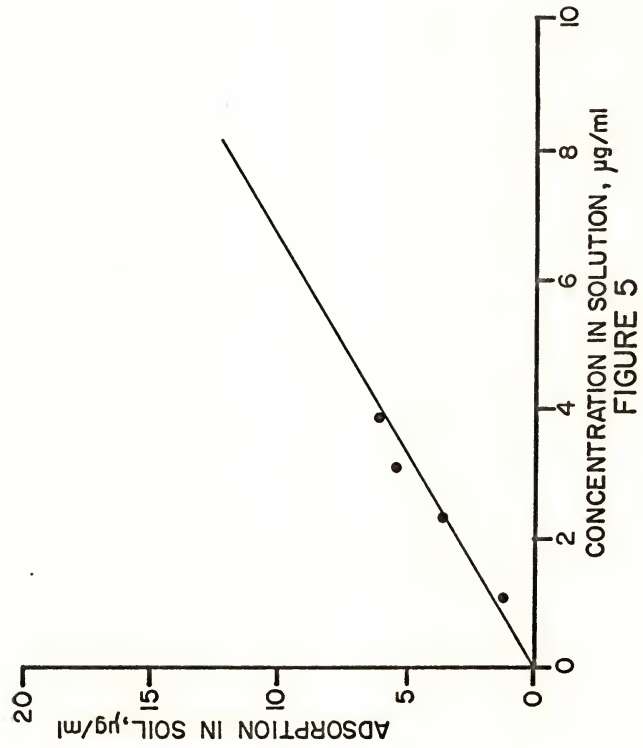


Table 4. Coefficient $m$ for 2, 4-D on different soil materials at equilibrium.

Soil

Glass beads

Lakeland fine sand

Fellowship subsoil

Everglades mucky peat m
34.20

7.86

0.67 
Figure 6. Experimental and calculated relative concentration distribution of 2, 4-D in glass beads at $30 \mathrm{~cm}$ length and $1.1 \mathrm{~cm} / \mathrm{h}$ flow velocity across the cross section. 


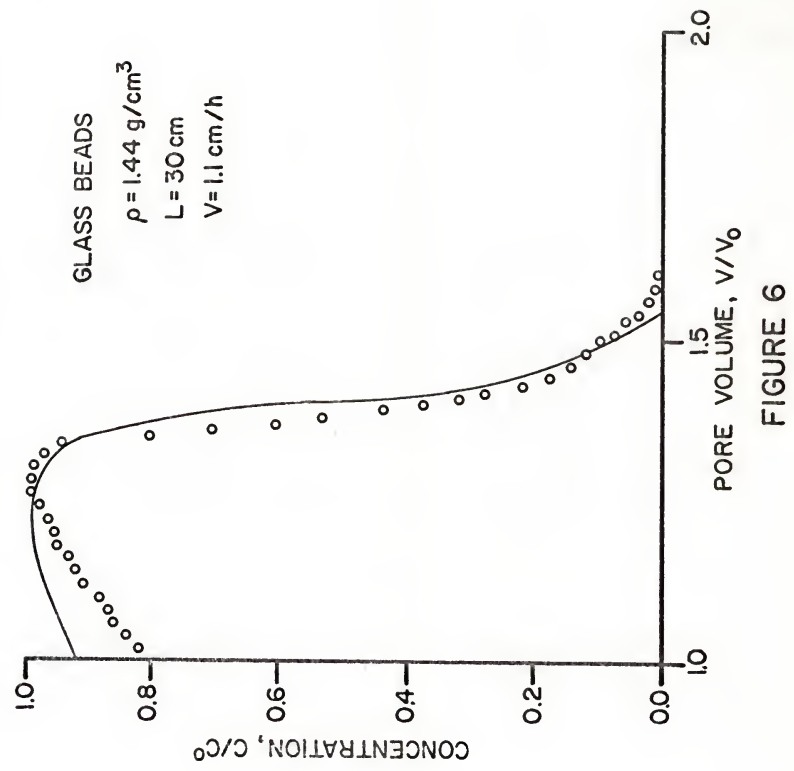


Figure 7. Experimental and calculated relative concentration distribution of $2,4-D$ in glass beads at $15 \mathrm{~cm}$ length and $1.1 \mathrm{~cm} / \mathrm{h}$ flow velocity across the cross section. 


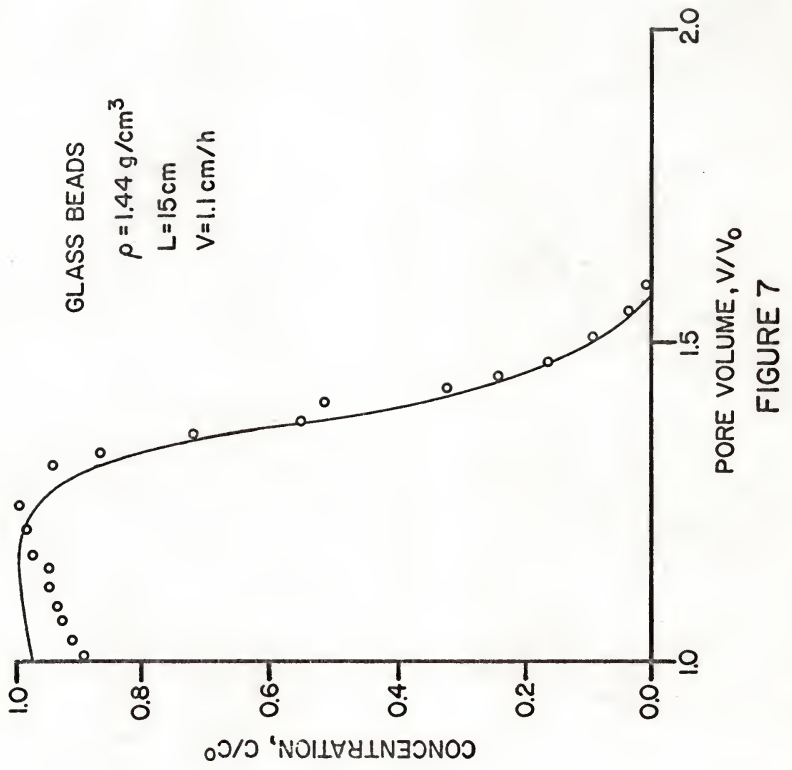


Figure 8. Experimental and calculated relative concentration distribution of $2,4-D$ in glass beads at $30 \mathrm{~cm}$ length and $2.2 \mathrm{~cm} / \mathrm{h}$ velocity across the cross section. 


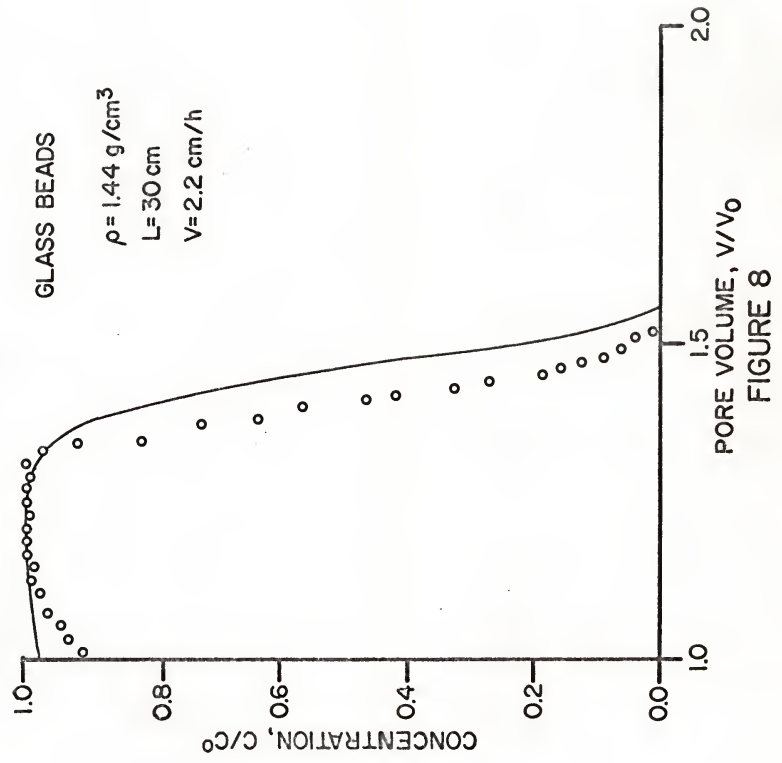


Figure 9. Experimental and calculated relative concentration distribution of 2, 4-D in glass beads at $15 \mathrm{~cm}$ length and $2.2 \mathrm{~cm} / \mathrm{h}$ velocity across the cross section. 


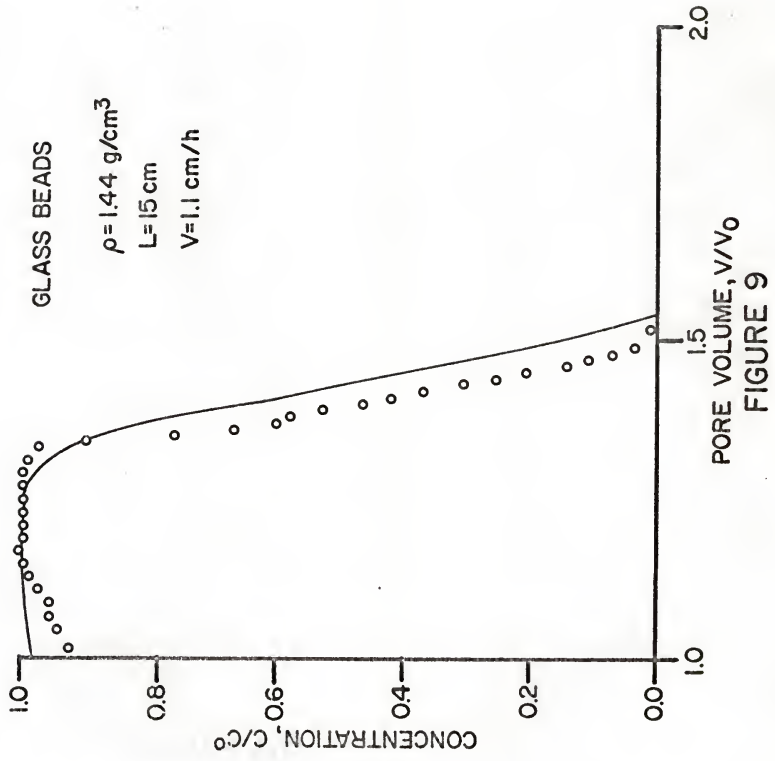


Figure 10. Experimental and calculated relative concentration distribution of 2, 4-D in Lakeland fine sand at $30 \mathrm{~cm}$ length and $1.1 \mathrm{~cm} / \mathrm{h}$ velocity across the cross section. 


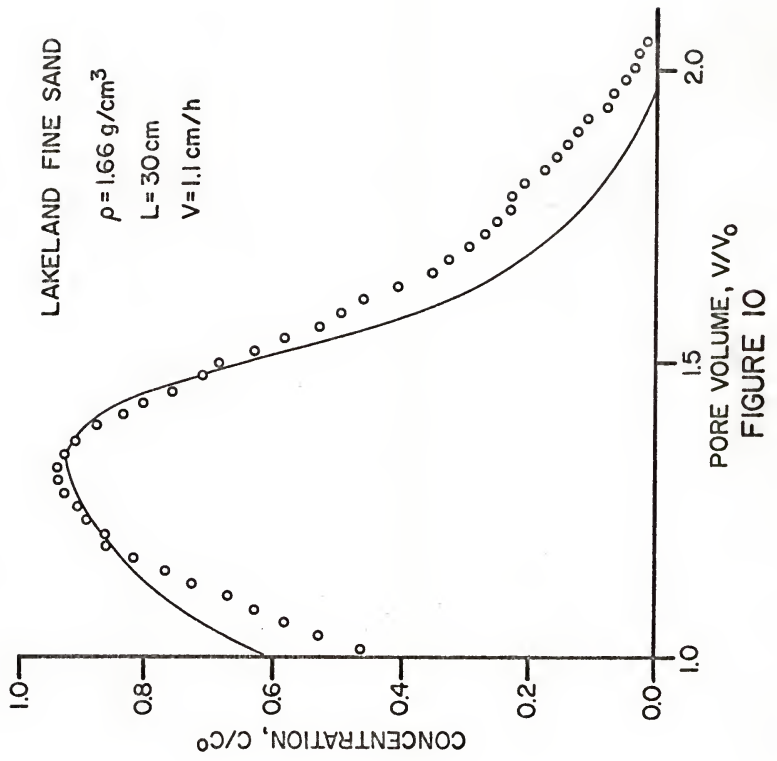


Figure 11. Experimental and calculated relative concentration distribution of 2, 4-D in Lakeland fine sand at $15 \mathrm{~cm}$ length and $1.1 \mathrm{~cm} / \mathrm{h}$ velocity across the cross section. 


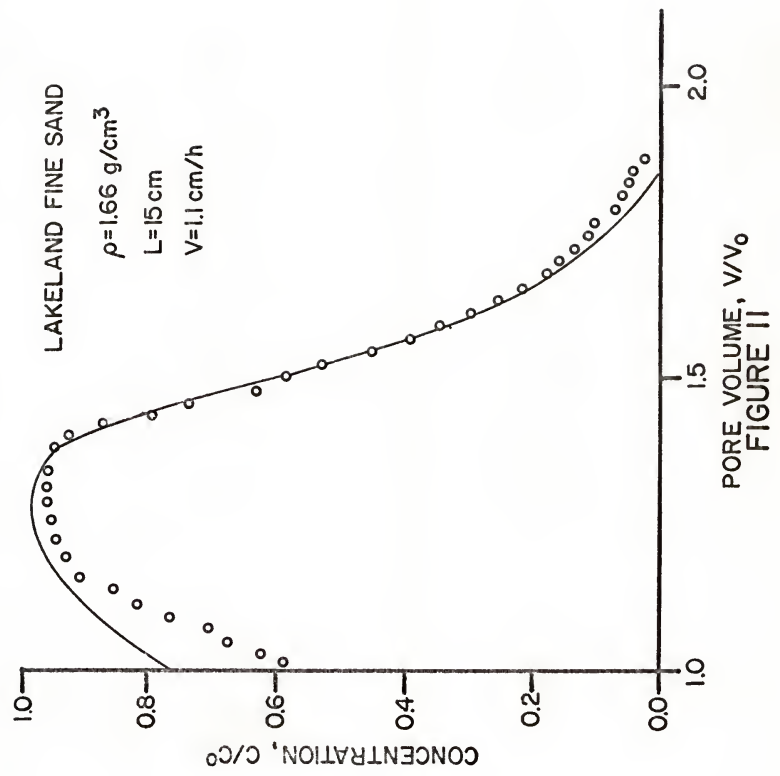


Figure 12. Experimental and calculated relative concentration distribution of $2,4-D$ in Lakeland fine sand at $30 \mathrm{~cm}$ length and $2.2 \mathrm{~cm} / \mathrm{h}$ velocity across the cross section. 


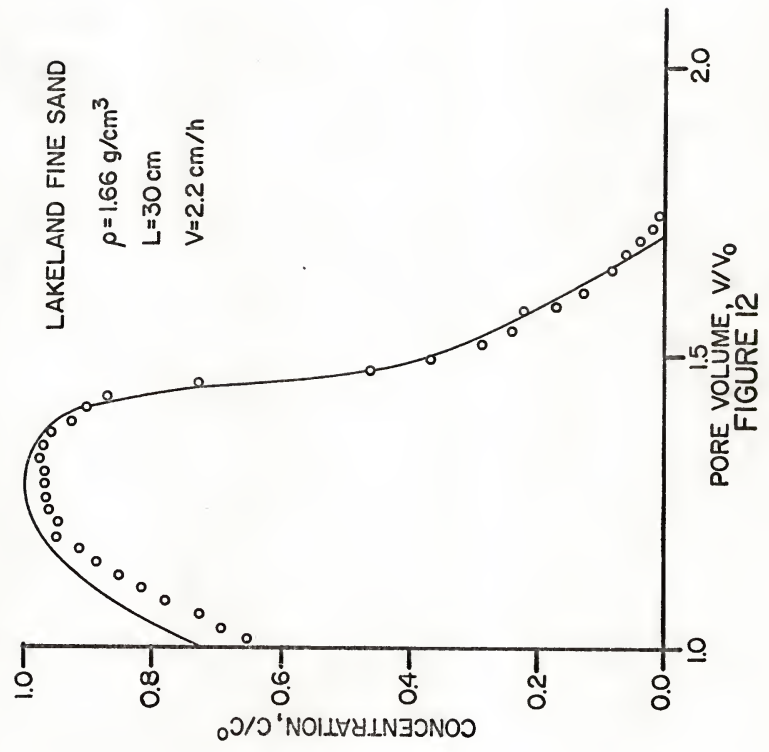


Figure 13. Experimental and calculated relative concentration distribution of 2, 4-D in Lakeland fine sand at $15 \mathrm{~cm}$ length and $2.2 \mathrm{~cm} / \mathrm{h}$ velocity across the cross section. 


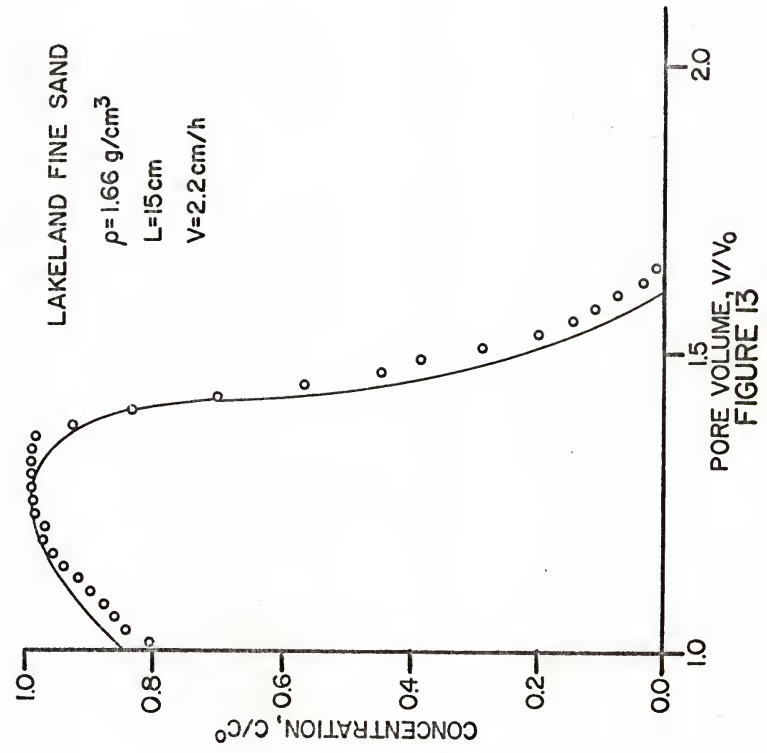


Figure 14. Experimental and calculated relative concentration distribution of 2, 4-D in Fellowship subsoil at $30 \mathrm{~cm}$ length and $1.1 \mathrm{~cm} / \mathrm{h}$ velocity across the cross section. 


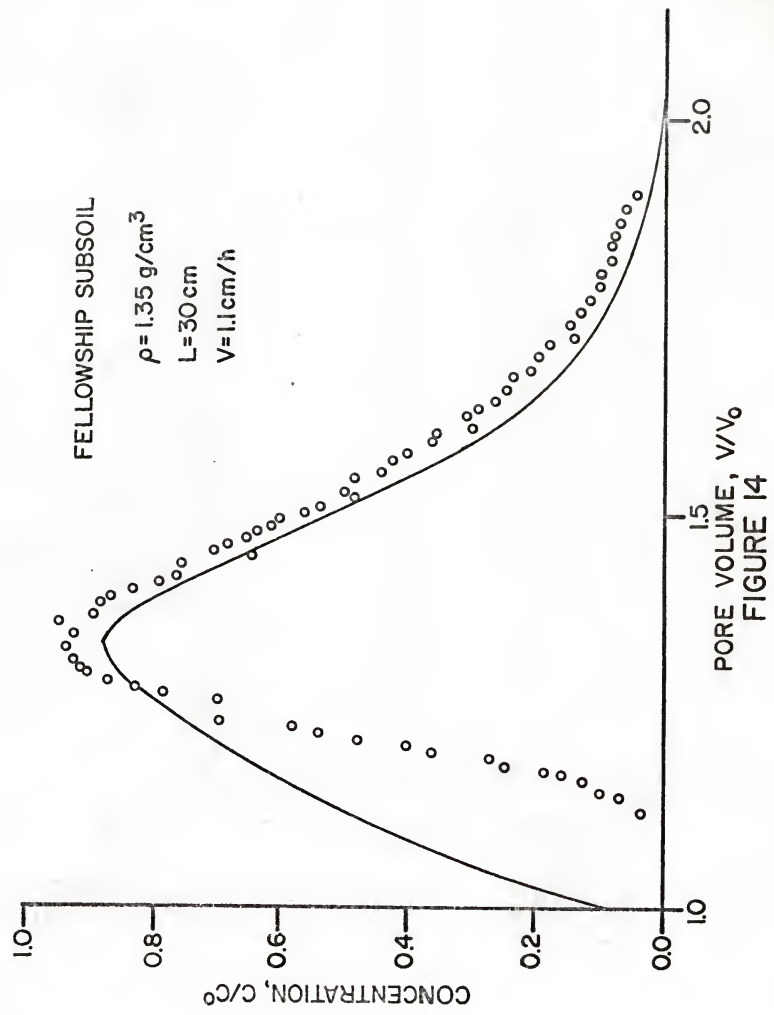


Figure 15. Experimental and calculated relative concentration distribution of 2, 4-D in Fellowship subsoil at $15 \mathrm{~cm}$ length and $1.1 \mathrm{~cm} / \mathrm{h}$ velocity across the cross section 


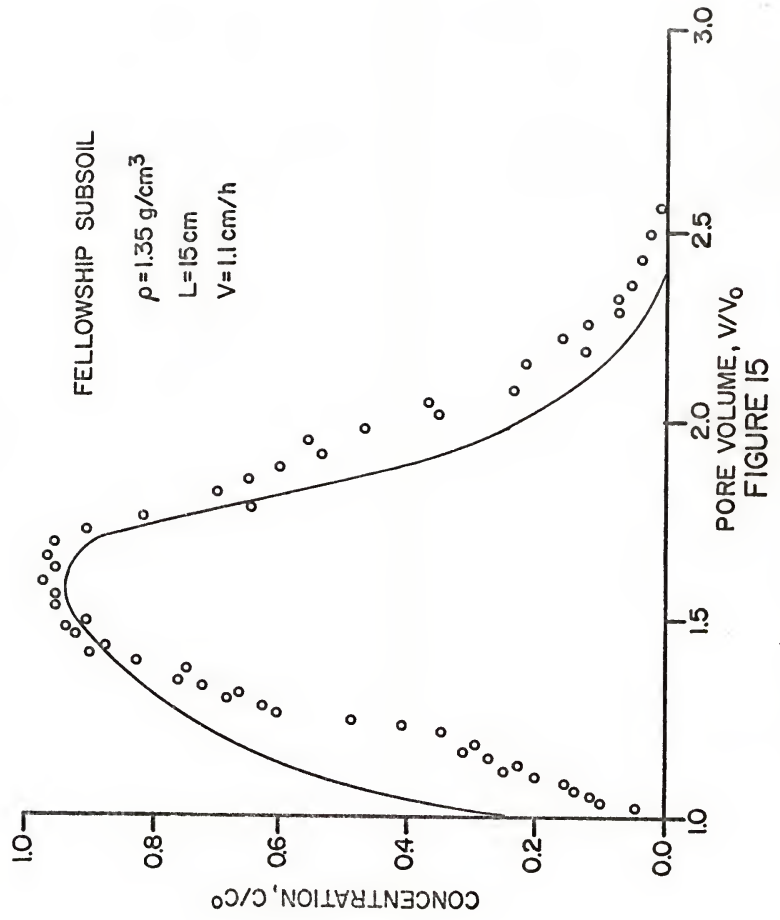


Figure 16. Experimental and calculated relative concentration distribution of 2, 4-D in Fellowship subsoil at $30 \mathrm{~cm}$ length and $2.2 \mathrm{~cm} / \mathrm{h}$ velocity across the cross section. 


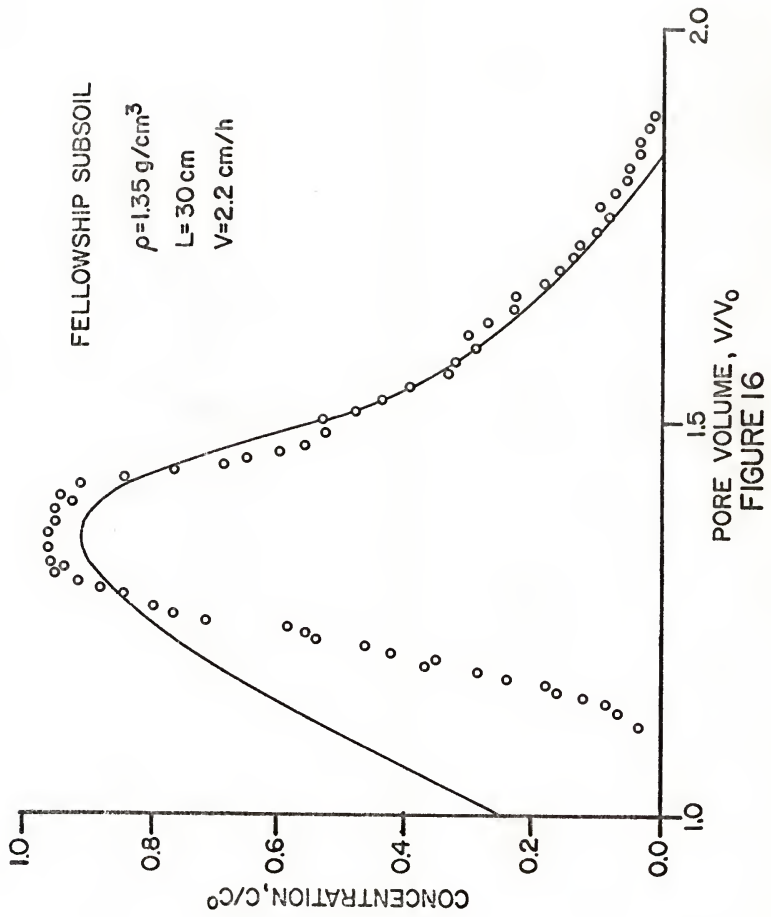


Figure 17. Experimental and calculated relative concentration distribution of 2, 4-D in Fellowship subsoil at $15 \mathrm{~cm}$ length and $2.2 \mathrm{~cm} / \mathrm{h}$ velocity across the cross section. 


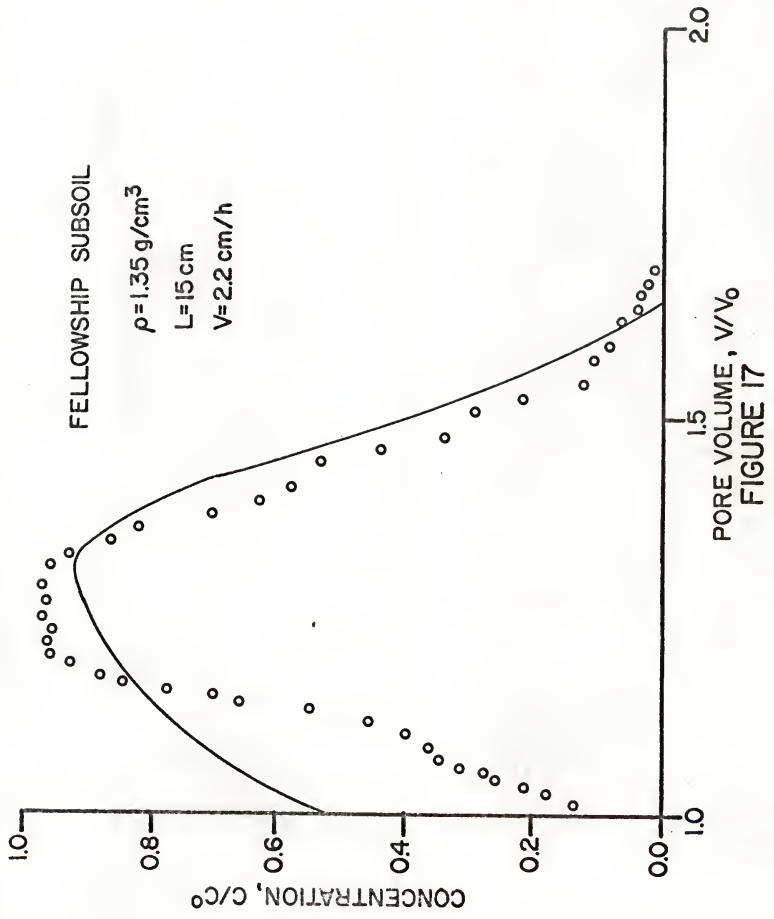


Figure 18. Experimental and calculated relative concentration distribution of 2, 4-D in Everglades mucky peat at $30 \mathrm{~cm}$ length and $1.1 \mathrm{~cm} / \mathrm{h}$ velocity across the cross section. 


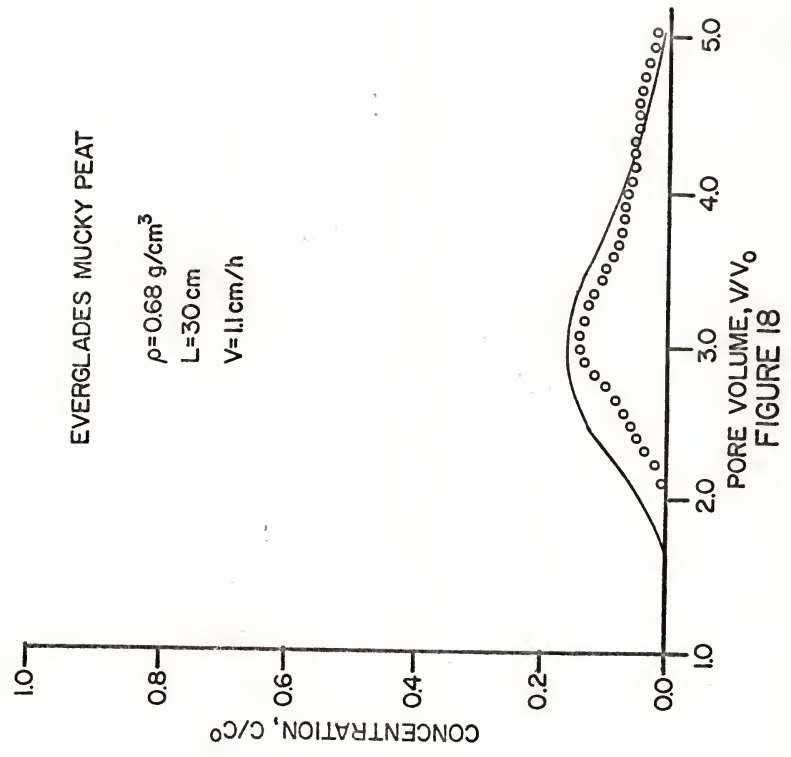


Figure 19. Experimental and calculated relative concentration distribution of 2, 4-D in Everglades mucky peat at $15 \mathrm{~cm}$ length and $1.1 \mathrm{~cm} / \mathrm{h}$ velocity across the cross section. 


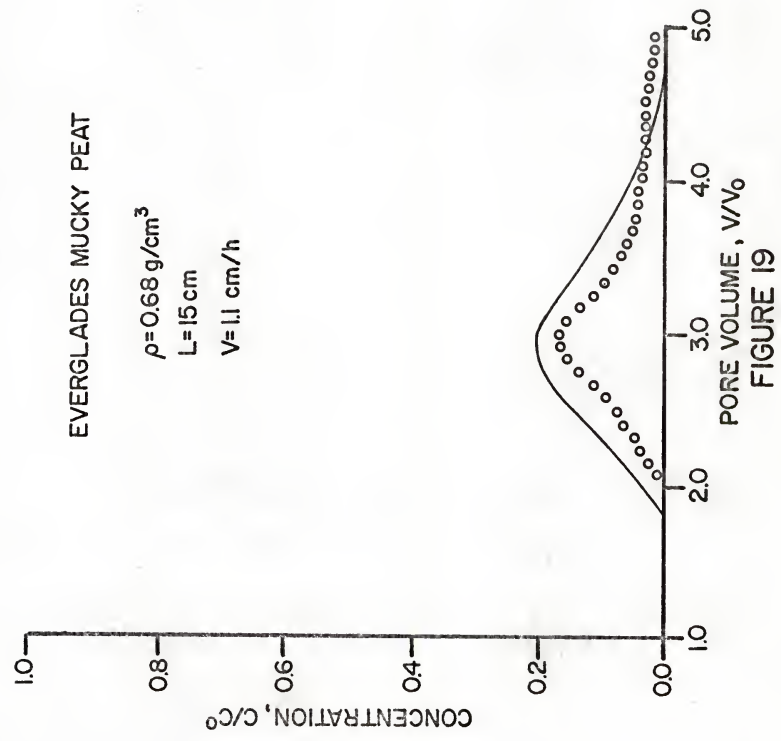


Figure 20. Experimental and calculated relative concentration distribution of 2, 4-D in Everglades mucky peat at $30 \mathrm{~cm}$ length and $2.2 \mathrm{~cm} / \mathrm{h}$ velocity across the cross section. 


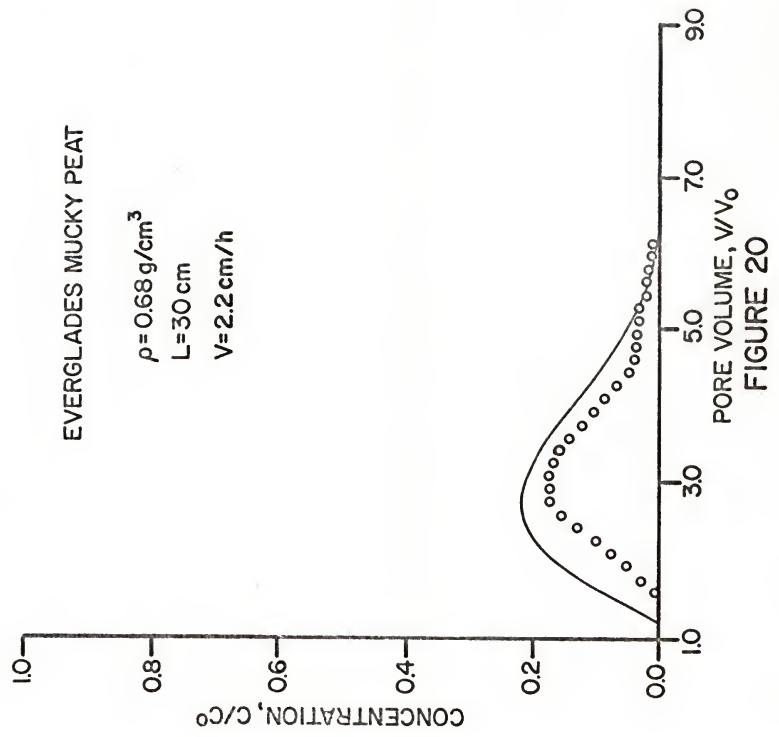


Figure 21. Experimental and calculated relative concentration distribution of 2, 4-D in Everglades mucky peat at $15 \mathrm{~cm}$ length and $2.2 \mathrm{~cm} / \mathrm{h}$ velocity across the cross section. 


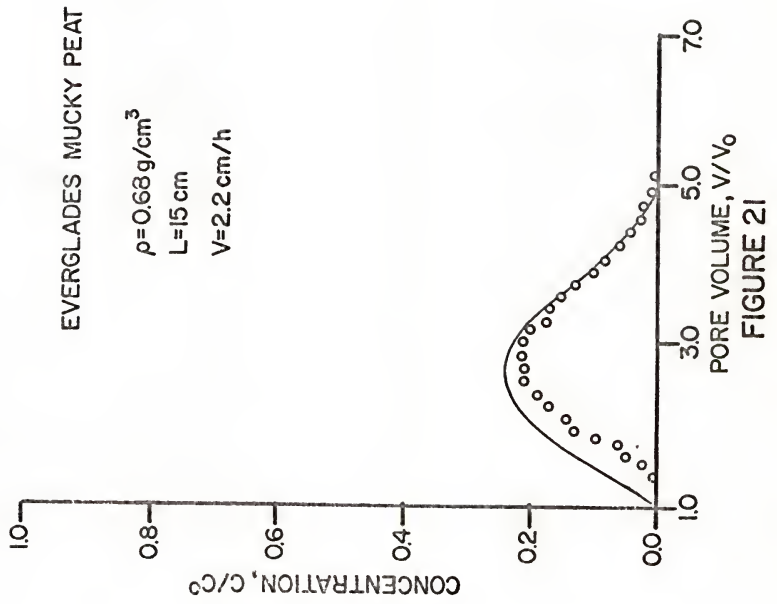


Table 5. Percentage recovery of 2, 4-D in the effluent from glass beads during displacement.

\begin{tabular}{lcc}
\hline $\begin{array}{c}\text { Velocity } \\
\mathrm{cm} / \mathrm{h}\end{array}$ & $\begin{array}{c}\text { Distance } \\
\mathrm{cm}\end{array}$ & $\begin{array}{c}\text { Recovery } \\
\%\end{array}$ \\
\hline 1.1 & 30 & 95.87 \\
1.1 & 15 & 97.53 \\
2.2 & 30 & 96.61 \\
2.2 & 15 & 98.05 \\
\hline
\end{tabular}


6,7 , and 8 .

Ratio of the distance traveled by the zone of highest concentration to the distance covered by the wetting front $\left(R_{f}\right)$ for the four soil materials are presented in Table 9. These values were obtained by dividing $30 \mathrm{~cm}$ by the distance traveled by the wetting front. This hypothetical distance covered by the wetting front was calculated as below:

$$
\begin{aligned}
& \text { Distance } \\
& \text { traveled by } \\
& \text { wetting front } \\
& \}=L^{\prime}=\frac{\text { Volume }}{\text { Area. }} \text { or } \\
& I^{\prime}=\frac{\mathrm{V}}{\mathrm{AE}} \\
& \text { where } V=\text { influent volume }\left(\mathrm{cm}^{3}\right) \\
& A=\text { cross sectional area of column }\left(\mathrm{cm}^{2}\right) \\
& \mathrm{E}=\text { porosity }
\end{aligned}
$$

\section{Degradation of $2,4-D$ in the Columns}

An attempt was made to determine if 2,4-D herbicide undergoes degradation in the soil columns when the displacing water contained $0.5 \%$ phenol by volume. The results of thin layer chromatographic analyses on the effluent samples are presented in Figure 3. In the figure, the numbers $1,7,8$, and 13 correspond to stock solution, 2 and 3 to effluent samples from glass beads, 4, 5, and 6 to mucky peat, 9 and 10 to Fellowship subsoil. Radioactivity in the chromatogram for the standard solutions and the effluents from all the soil materials moved with the 2,4 D molecules and to approximately equal distances from the starting point. The $R_{f}$ value (ratio of distance traveled by the zone of concentration to that by the 
Table 6. Percentace recovery of 2, 4-D in the effluent from Lakeland fine sand during displacement.

\begin{tabular}{ccc}
$\begin{array}{c}\text { Velocity } \\
\mathrm{cm} / \mathrm{h}\end{array}$ & $\begin{array}{c}\text { Distance } \\
\mathrm{cm}\end{array}$ & $\begin{array}{c}\text { Recovery } \\
\%\end{array}$ \\
\hline 1.1 & 30 & 89.38 \\
1.1 & 15 & 90.89 \\
2.2 & 30 & 90.14 \\
2.2 & 15 & 91.36 \\
\hline
\end{tabular}


Table 7. Percentage recovery of 2, 4-D in the effluent from Fellowship subsoil during displacement.

\begin{tabular}{ccc}
$\begin{array}{c}\text { Velocity } \\
\mathrm{cm} / \mathrm{h}\end{array}$ & $\begin{array}{c}\text { Distance } \\
\mathrm{cm}\end{array}$ & $\begin{array}{c}\text { Recovery } \\
\%\end{array}$ \\
\hline 1.1 & 30 & 84.58 \\
1.1 & 15 & 85.12 \\
2.2 & 30 & 86.81 \\
2.2 & 15 & 89.06 \\
\hline
\end{tabular}


Table 8. Percentage recovery of $2,4-D$ in the effluent from Everglades mucky peat during displacement.

\begin{tabular}{ccc}
$\begin{array}{c}\text { Velocity } \\
\mathrm{cm} / \mathrm{h}\end{array}$ & $\begin{array}{c}\text { Distance } \\
\mathrm{cm}\end{array}$ & $\begin{array}{c}\text { Recovery } \\
\%\end{array}$ \\
\hline 1.1 & 30 & 58.31 \\
1.1 & 15 & 66.54 \\
2.2 & 30 & 62.63 \\
2.2 & 15 & 69.77 \\
\hline
\end{tabular}


Table 9. $R_{f}$ values of 2, 4-D for four soils during the displacement at the flow velocities.

\begin{tabular}{llc}
\hline Soil & \multicolumn{2}{c}{$\mathrm{R}_{f}$ Value } \\
\cline { 2 - 3 } glass beads & 0.967 & $2.2 \mathrm{~cm} / \mathrm{h}$ \\
\hline Lakeland fine sand & 0.913 & 0.983 \\
Fellowship subsoil & 0.755 & 0.938 \\
Everglades mucky peat & 0.434 & 0.789 \\
\end{tabular}


wetting front) is found to be 0.67 . If there was any degradation of the herbicide in the soil columns, radioactivity would have distributed along the chromatogram in the form of a streak or a string of small globules each globule representing one degraded product. In that case a quantitative estimation of radioactivity in the chromatogram would have been necessary to assess the amount of pure 2,4-D.

Thin layer chromatographic analyses of effluent samples from all porous material qualitatively indicate that 2,4-D did not disintegrate during elution from columns of the porous media.

\section{Adsorption of 2,4-D on Soils}

Results of adsorption isotherms on glass beads, Lakeland fine sand and Fellowship subsoil under equilibrium conditions are presented in Figure 4 and those on Everglades mucky peat in Figure 5.

In all the soils and the glass beads a linear relationship was found between herbicide concentration in solution and adsorption. Maximum isotherm slope and thus the greatest adsorption is observed in Everglades mucky peat, followed in descending order by Fellowship subsoil, Lakeland sand and glass beads. The values of coefficient $m$ obtained from the best visual fitting straight line are presented in Table 4. It could be expected from Figure 5 and Table 4 that greater adsorption in the organic soil results in a sparing release of 2,4-D from the columns during displacement. It will also spread the concentration while slowing down the zone of highest concentration far behind the wetting front. A higher value for $m$ as in glass beads indicates that the herbicide should move readily with the flowing water.

\section{Movement of 2,4-D in glass beads}

The 2,4-D elution curves showing concentration as a function of 
pore volume from 105-210 $\mathrm{m}$. glass beads for flow velocities of 1.1 and $2.2 \mathrm{~cm} / \mathrm{h}$ are shown in Figures $6,7,8$, and 9 . The relative concentrations in effluent at $30 \mathrm{~cm}$ for the two velocities are in Figures 6 and 8 while those at $15 \mathrm{~cm}$ are in Figures 7 and 9. Pore volume, Vo, for the glass beads system was $490.45 \mathrm{ml}$. Since the total volume of the empty column was $1362 \mathrm{ml}$, the average water velocity in the pores was 3.05 and 6.10 $\mathrm{cm} / \mathrm{h}$.

The herbicide noved readily through the glass beads. The solid lines in the figures represent theoretical curves and were calculated from equation 3.25 for the $\mathrm{K}$ value of 0.006 hours $^{\mathrm{I}}$. These $\mathrm{K}$ values which represent the rate at which the adsorption process attained equilibrium were not determined experimentally. In the equation 3.25 all the parameters except $\mathrm{K}$ were determined experimentally. Appropriate values for $\mathrm{K}$ were obtained through trial calculation of equation 3.25 calculated by using a program written for numerical integration in Fortran IV (G) language and an IBM 360 system. Values of $\mathrm{K}$ were chosen to obtain a good visual fit between calculated and experimental curves.

Observed relative concentration $\mathrm{C} / \mathrm{C}^{\circ}$ in the initial sample coming out of the column is 0.82 and the ratio quickly reaches 1 before dropping gradually. Breakthrough curves are not symmetrical around the concentration zone. Skewness to the right is observed. Calculated curves for the initial time periods seem to over estimate. Near the peak of the breakthrough curves the calculated values make better estimation. At the far right there is generally under estimation since the theoretical values drop to zero rapidly while the experimental values go little further to zero gradually.

The quantity of 2,4-D recovered in the effluent (Table 5) ranged from 95.87 to $98.05 \%$. Lower recovery was observed in the effluent at lower 
flow velocity.

The $R_{f}$ value was 0.967 at $1.1 \mathrm{~cm} / \mathrm{h}$ and 0.983 at $2.2 \mathrm{~cm} / \mathrm{h}$ flow velocity. $R_{f}$ values for glass beads and all the soils are presented in Table 9. It is interesting to note that $R_{f}$ values for 2,4-D at two different velocities are not the same. Slightly higher value was observed at $2.2 \mathrm{~cm} / \mathrm{h}$ velocity. Similar observation has been made by Giddings, 1965 and Snyder, 1968. These values do not seem to have any relation with $\mathrm{K}$ since the peak was reached almost at the same time for any chosen value ofK in the calculations, but the $R_{f}$ values increase with increasing values of $m$ as predicted by the following:

$$
\text { partition coefficient }=\left(\frac{1}{m}\right)=\frac{1-R_{f}}{R_{f}} \quad \text { given }
$$

by Lederer and Lederer (1957).

The calculated and observed values during time periods past the concentration peak in Figures 6 and 7 seem to go together except near the tail end where the calculated values under-estimate. Such an extended tailing could be attributed mainly to two processes; molecular diffusion and hysteresis between adsorption and desorption processes.

Although molecular diffusion is very small for organic chemicals according to Hartley, 1964, it may show some effect in the long run. By the time the boundary between herbicide solution and water travels from the point of introduction to the point of exit it took 9.82 hours. So some spreading due to diffusion is expected.

It has been assumed in most of the miscible displacement studies (Nielsen and Biggar, 1963; Miller, et a1., 1965; Lindstrom, et al., 1967; Davidson, et a1., 1968 and Kay and Elrick, 1967) that the partition coefficient has the same value at equilibrium during adsorption or desorption. 
The same assumption is made here for simplicity. Some hysteretic effect of Atrazine on soils has been reported by Swanson and Dutt, 1970. Similar effect might be show by 2,4-D.

Patterns of 2,4-D displacement in glass beads at a velocity of $2.2 \mathrm{~cm} / \mathrm{h}$ across the cross section at $30 \mathrm{~cm}$ and $15 \mathrm{~cm}$ distance (Figures 8 and 9) differ slightly. Here the observed relative concentration starts with a higher ratio than that when the velocity was $1.1 \mathrm{~cm} / \mathrm{h}$ and reaches 1 quickly and stays until the concentration drops rapidly. This behavior of almost piston displacement pattern indicates that the extent of adsorption of 2,4-D is very slight. Recovery of the herbicide at $30 \mathrm{~cm}$ was $96.61 \%$ and at $15 \mathrm{~cm}$ was $98.05 \%$ (Table 5). These values are slightly higher than the recovery at $1.1 \mathrm{~cm} / \mathrm{h}$ for their respective distances. Calculated concentrations are higher than observed during early time periods. This trend was similar at $1.1 \mathrm{~cm} / \mathrm{h}$ velocity. Almost perfect fit is observed near the zone of highest concentration. Observed values, however, drop too quickly compared to the calculated ones, resulting in a poor fit. This is apparently due to very little retention in the glass beads during water movement.

Collecting samples at $15 \mathrm{~cm}$ depth was accomplished with a vacuum device. This helps in understanding the displacement processes as happening in the profile. It is also possible to draw concentration profiles in the soil column at given times with a number of sampling locations in the columns. This method worked satisfactorily as indicated by smooth breakthrough curves.

\section{Movement of 2,4-D in the Soils}

Soils as a group behaved quite differently from the glass beads in transporting 2,4-D during constant flux infiltration. In general there 
was more adsorption and as a result more spreading of breakthrough curves. Adsorption in mineral soils like Lakeland fine sand and Fellowship subsoil was not too much greater than what it was in glass beads. Recovery percentage in Lakeland fine sand ranged from 89.38 to $91.36 \%$ (Table 6) and in Fellowship subsoil it was 84.58 to $89.06 \%$ (Table 7), but it was only 58.31 to $65.77 \%$ for mucky peat soil (Table 8 ). Lakeland fine sand and Fellowship subsoil, being mineral soils, have a net negative charge on their surface and have less attraction towards 2,4-D molecules which behave like anions (Scott and Iutz, 1971). Mucky peat being mostly organic matter carries some positive charge in addition to high negative charge. The positive charge therefore attracts the 2,4-D molecules and hinders the free movement through the profile. There also seems to be some irreversible adsorption of 2,4-D by the mucky peat. This is evident from the recovery of only 58.31\% even after the prolonged elution of 4 pore volumes. In mineral soils and glass beads herbicide was recovered within one pore volume of elution process. The separation process is very distinct in the mucky peat. The $R_{f}$ value was only 0.434 at $1.1 \mathrm{~cm} / \mathrm{h}$ and 0.440 at $2.2 \mathrm{~cm} / \mathrm{h}$ velocity. These values ranged very high for Lakeland fine sand and Fellowship subsoil (Table 9). There was an increase in $R_{f}$ values for all soils at higher velocities, probably attributable to less contact time of 2,4-D with pore wall surfaces at faster flow velocities. The same tendency was observed for glass beads also.

Elution of 2,4-D through Lakeland Fine Sand

Experimental curves look smooth during all time periods at velocity $1.1 \mathrm{~cm} / \mathrm{h}$ for both $30 \mathrm{~cm}$ and $15 \mathrm{~cm}$ lengths (Figures 10 and 11 ). The first sample showed a relative concentration of 0.46 at $30 \mathrm{~cm}$ length and 0.58 at $15 \mathrm{~cm}$ length. The recovery of applied 2,4-D was found to be $89.38 \%$ 
at $30 \mathrm{~cm}$ and 90.89 at $15 \mathrm{~cm}$ length. The breakthrough curves for $2.2 \mathrm{~cm} / \mathrm{h}$ velocity are presented in Figures 12 and 13. Here also, the experimenta1 curves are smooth. Slightly higher recovery was observed compared to that at lower flow velocity. Theoretical curves for both velocities were calculated according to equation 3.25 for $\mathrm{K}$ of 0.07 hours $^{1}$. Calculated values overestimate in the early stage of elution. But a good estimate is made around the zone of highest concentration. Near the tail end the calculated values underestimate generally at both distances and velocities. These discrepancies have been discussed earlier for glass beads. The same reasons could be attributed here also. In the sandy soils like Lakeland fine sand the herbicide moved in high concentration almost with the water flowing in the profile. There is a great danger that the surface applied chemicals will readily wash away from the soil and join the drainage water thus polluting the streams and lakes.

\section{Elution of 2,4-D through Fellowship Subsoil}

Experimental and calculated elution curves of 2,4-D through Fellowship subsoil are presented in Figures 14, 15, 16, and 17. Effluent concentration in the experiments at $1.1 \mathrm{~cm} / \mathrm{h}$ flow velocity was found to be zero for the first $30 \mathrm{ml}$ of effluent. After this, the relative concentration rose to nearly 1 and dropped gradually, giving a distinct skewed appearance. The fact that zero concentration was observed in the initial samples reveals a large degree of adsorption, thereby retarding the zone of highest concentration to a fraction 0.755 of the distance covered by the wetting front. Although Fellowship sibsoil is mainly a mineral soil and should have no greater affinity than the Lakeland fine sand, a greater retention is observed. Fellowship subsoil had a clay content of $27.3 \%$ and therefore had considerably high specific surface area compared to Lakeland 
fine sand which had only $2 \%$ clay. A high retention of 2,4-D in Fellowship subsoil seems to be due to adsorption of herbicide molecules on the surface of the mineral during wetting of mineral by the herbicide solution. This might be due to some positive charge on the organic matter thus giving.a recovery of 84.58 to $89.06 \%$ (Table 7).

Theoretical curves were calculated for $\mathrm{K}=0.216$ hours $^{-1}$. Here also the theoretical curves overestimate the relative concentration in the early stages. The general fit seems to be satisfactory for the remainder. Experimental values drop gradually compared to calculated as in the earlier cases. In Fellowship soils with the sandy clay subsoil, we encounter an interesting situation. Herbicide from the sandy surface layer will leach readily as we saw in Lakeland fine sand. Once the water comes in contact with subsoil, water flow will be reduced and at the same time herbicide will be retained.

Under lower precipitation rates, herbicide will move vertically down and it will be retained in the subsoil for sometime. Only under prolonged precipitation is it likely that the chemical will move out of the soil and pollute the water going into streams and lakes. Under high precipitation rate however there is greater danger of washing the chemical from the top layer into the stream water since there will be little penetration of water into the subsoil.

Elution of 2,4-D through Everglades mucky peat

Among the three soils used in the studies, mucky peat showed the greatest adsorption of 2,4-D. Reciprocal of the slope of adsorption isotherm at equilibrium was found to be 0.67 (Table 4) compared to 108.04 for the glass beads. Such a powerful adsorption could result from the affinity of positive charge of the organic matter towards the negatively 
charged 2, 4-D molecules.

The elution curves of 2/4-D in Everglades mucky peat are presented in Figures 18, 19, 20, and 21. One striking fact about these results is the concentration distribution of $2,4-\mathrm{D}$ in the effluent. No herbicide was detected in the effluent until a whole pore volume of liquid was collected. Herbicide then appeared in a very low concentration and it spread over 3 pore volumes with highest concentration ratio $\left(\mathrm{C} / \mathrm{C}^{\circ}\right)$ of only 0.140 during displacement with flow velocity of $1.1 \mathrm{~cm} / \mathrm{h}$. At the same velocity the concentration ratio at $15 \mathrm{~cm}$ distance reached a high of 0.185. Breakthrough was also earlier for $15 \mathrm{~cm}$ distance than for $30 \mathrm{~cm}$ distance. Pattern of displacement at both distances seemed to be similar. During the flow velocity of $2.2 \mathrm{~cm} / \mathrm{h}$ the herbicide appeared in the effluent a little earlier and also reached a slightly higher concentration ratio of 0.190 at $30 \mathrm{~cm}$ and 0.22 at $15 \mathrm{~cm}$ distance. Recovery of 2,4-D from mucky peat during flow velocity of $1.1 \mathrm{~cm} / \mathrm{h}$ was $58.31 \%$ at $30 \mathrm{~cm}$ and $60.54 \%$ at $15 \mathrm{~cm}$ distance. It was slightly higher and reached $62.63 \%$ and $65.77 \%$, respectively when the flow velocity was doubled. Such a low recovery at either speed indicates that displacement was still not complete due to greater retention. This was particularly so at lower flow velocity since the low concentration ratio was observed after 4 pore volume of effluent. Concentration did seem to reach zero at faster flow velocity. Still the recovery was $62.63-65.77 \%$. This seems to suggest that there was some irreversible adsorption of $2,4-D$ on the mucky peat.

The theoretical curves were calculated for $\mathrm{K}=.75$ hours $^{-1}$. They seem to over estimate for all the elution runs except near the tail end where they dip a little faster than the observed values. Peak for the calculated and the observed breakthrough curves fall at about the same 
time. The prolonged tailing of experimental concentrations that was discussed earlier seems to prevail here also indicating effects of diffusion and hysteresis of partition coefficient.

Surface applied herbicides like 2,4-D in organic soils are retained in the top layers during normal water movement caused by rainfall or irrigations. There is little danger of removal of chemical deep in the profile.

Seepage water joining the rivers and lakes is also not likely to carry the herbicide extensively. 


\section{SUMMARY AND CONCLUSIONS}

Miscible displacement of dilute ${ }^{14} \mathrm{C}$ labeled 2,4-D herbicide

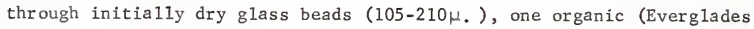
mucky peat) and two mineral soils (Lakeland fine sand and Fellowship subsoil), was studied under conditions of constant liquid influx. The experimental data were compared to a mathematical model which was based upon adsorption parameters with diffusion assumed negligible for the concentration range of $2,4-D$ in the effluent. The model incorporates the commonly used partition coefficients (ratio of concentrations in adsorbed to solution phases) from adsorption isotherms and the rate of adsorption which is newly introduced here.

The flow system consisted of lucite column packed with air dry porous material. During an experiment the column was placed vertically in a constant temperature chamber. Studies were made at two liquid flow velocities. Herbicide solution was introduced at the required flow rate from the bottom of the air dry column. Constant flow velocity was maintained by means of two positive displacement pumps. One pump was used for herbicide solution and the other was used for pure water. Initially $200 \mathrm{ml}$ of solution was introduced into the column immediately followed by pure water displacing the solution through the column. Phenol was added to the water to provide concentration of $0.5 \%$ for preventing possible degradation of $2,4-D$ during movement through the soil. 
Effluent coming out of the column was collected in fractions of $5 \mathrm{ml}$ each with the help of an automatic fraction collector. Soil solution was extracted periodically from a porous extraction cup located in the soil at $15 \mathrm{~cm}$ depth. The extract was collected in 25 microliter volume fractions under partial vacuum. Concentrations of 2,4-D in effluent and extract samples were determined by liquid scintillation counting. Random effluent samples were subjected to additional analyses by thin layer chromatography to determine if degradation of the herbicide occurred. The lack of fit between the initial stages of the experimental and calculated curves was attributed to higher adsorption of solute on the porous material during movement of wetting front compared to adsorption in saturated medium. As the wetting front of herbicide solution moved through dry soil, sorption rapidly removed herbicide out of solution. Thus, a concentration gradient becomes established with time in the solution behind the wetting front and diffusion tends to move herbicide towards the wetting front. A diffusion term would probably aid the model in more accurately predicting the initial portion of the curve. Near the end of the elution process however, predicted values are lower than observed values. This tailing effect also seems to be due to diffusion which is at work all along.

Herbicide moved very readily through glass beads and very little evidence was observed for irreversible adsorption. Calculated and experimental results of 2,4-D displacement through Lakeland fine sand and Fellowship subsoil also indicated that the calculated curves overestimated the concentration before the peak is reached, with a fairly good estimation near and after the peak. In these two mineral soils, the concentration peak was reached slightly earlier at higher flow velocity. Quantities of applied herbicide recovered in the effluent were also fairly high at the higher flow 
rate. Ready movement of 2,4-D through mineral soils suggests that the herbicide behaved like an anion. This was also observed by Weber, et al., 1965, and Scott and Lutz, 1971. An anion will have very little affinity towards the negatively charged mineral soils. The elution curves were markedly different for Everglades mucky peat. Novement of herbicide was restricted due to a high adsorption rate and as a result the concentration was spread out over a larger volume of effluent. Relative concentration $\mathrm{C} / \mathrm{C}^{\circ}$ at the peak of the curve was found to be only 0.2 whereas it reached almost 1.0 for glass beads, Lakeland fine sand and Fellowship subsoil. Predicted curves gave higher estimations in the first half of the curves, while giving better estimates later. Experimental values however were prolonged after calculated curves reached zero. Herbicide recovery was less than $60 \%$ of the applied amount at either velocity. This was quite low compared to the mineral soils and the glass beads where more than $90 \%$ was recovered in the effluent. The low recovery of 2,4-D from the mucky peat suggests that irreversible adsorption occurred. This adsorption probably resulted due to stronger attraction of herbicide molecule to positively charged sites on the organic soil.

In conclusion, 2,4-D herbicide when applied on the soil surface for the purpose of killing broad leaf weeds showed a great deal of mobility in the mineral soils. It moved readily through the mineral soils, much more so in sandy soils without organic matter. Organic matter content in the soil seemed to reduce the mobility in the profile. In sandy soils there is some danger of 2,4-D moving with the ground water endangering the aquatic plants growing in streams and lakes.

Organic soils offer high resistance to the movement of surfaceapplied herbicides like 2,4-D. Even large amounts of precipitation cannot 
effectively carry the herbicide very far down the profile. It is not likely that drainage water from organic soils would contain dangerous levels of 2,4-D.

Theory developed here seems to describe quite well 2,4-D movement in soils under imposed conditions of high flow velocities, no chemical or microbiological degradation, and no irreversible adsorption. 
ARPENDIX 


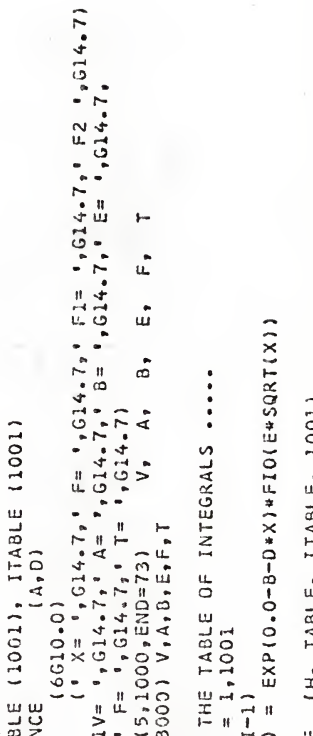

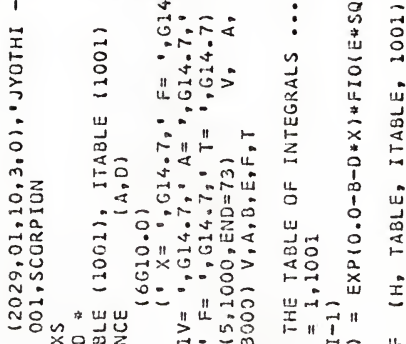

O Uुok出

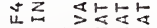

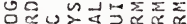
c 0 w

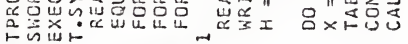

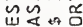

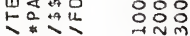
000

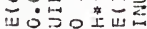

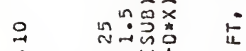
$\rightarrow 0+n c$

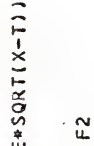
* 0 w

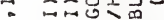

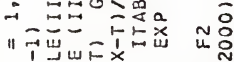

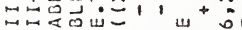

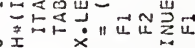

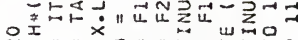

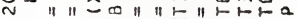
ㅇ $\rightarrow$ Nu 穴

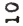
in $\stackrel{m}{N}$

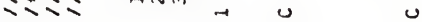




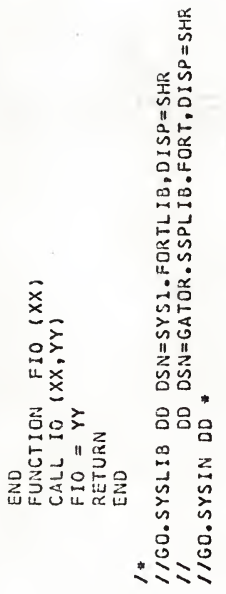




\section{LITERATURE CITED}

Abdel-Aziz, H. M. and S. A. Taylor. 1965. Simultaneous flow of water and salt through unsaturated porous media: I. Rate equations. Soil Sci. Soc., Am. Proc. 29:141-143.

Audus, L. J. 1964. Herbicide behavior in the soil. pp. 163-206. In Audus (ed.). The physiology and biochemistry of herbicides. Academic Press, London.

Bal1, W. E. and O. C. French. 1935. Sulfuric acid for control of weeds. Calif. Agr. Exp. Sta. Res. Bul1. 254:113-144.

Biggar, J. W. and D. R. Nielsen. 1967. Miscible displacement and leaching phenomenon. In Irrigation of Agricultural Lands. Agronomy 11:254-274.

Bray, G. A. 1960. A simple efficient liquid scintillator for counting aqueous solutions in a liquid scintillation counter. Ana 1. Biochem. 1:279-285.

Brenner, H. 1962. The diffusion model of longitudinal mixing in beds of finite length. Numerical Values Chem. Engr. Sc. $17: 229-243$.

Brian, R. C. 1964. The classification of herbicides and types of toxicity. pp. 1-37. In L. J. Audus (ed.). Physiology and biochemistry of herbicides. Academic Press, London.

Brown, J. W. and J. W. Mitchell. 1948. Inactivation of 2,4-D in soils as affected by soil moisture temperature, manure and autoclaving. Bot. Gaz. 109:314-323.

Buckingham, E. 1904. Contributions to our knowledge of the aeration of soils. U. S. D. A. Bureau of Soils Bull. 22 pp. 7-52.

Burnside, O. C., E. L. Schmidt and R. Behrens. 1961. Dissipation of simazine from the soil. Weeds 9:477-484.

C. R. Fenstre and G. A. Wicks. 1963. Dissipation and leaching of monuron, simazine and atrazine in Nebraska soils. Weeds 11:209-213.

Ca11, F. 1957. Soil funigation IV. J. Sci. Food Ag. 8:137-142. 
Ca11, F. 1957. Soil fumigation V. J. Sci. Food Ag. 8:143-150.

Chandra, P., W. R. Furtick and W. B. Bollen. 1960. The effects of four herbicides on microorganisms in nine Oregon soils. Weeds $8: 589-598$.

Churchill, R. V. 1958. Operational Mathematics,. 2nd. Ed. McGraw-Hill. New York.

Corey, J. C., D. R. Nielsen and J. W. Biggar. 1963. Miscible displacement in saturated and unsaturated sandstone.

Soil Sc. Soc. Amer. Proc. 27:258-262.

Crafts, A. S. and H. Drever. 1960. Experiments with herbicides in soils. Weeds $8: 12-18$.

Davidson, J. M., C. E. Rieck, and P. W. Santelman. 1968. Influence of water flux and porous material on the movement of selected herbicides. Soil Sc. Soc. Amer. Proc. 32:629-633.

, and P. W. Santelman. 1968. Displacement of

Fluometuron and Diuron through saturated glass beads and soil. Weed Sc. 16:544-548.

Davis, F. L. and F. L. Selman. 1954. Effects of water upon the movement of Dinitro weed killers in soils. Weeds 3:11-20.

Day, P. R. 1956. Dispersion of a moving salt-water boundary advancing through saturated sand. Trans. Amer. Geophys Union. 37:595-601.

Del Pozo, Jenaro. 1959. Determination of the adsorption and movement of 2,3,6-trichlorobenzoic acid in soil as influenced by soil type and water percolation.

Oregon State College, Library, Corvallis. 73 p.

Evans, G. N. and I. Levin. 1969. The distribution of salt by infiltration of water into dry soil and sand. Aust. J. Soil Res. $7: 21-27$.

Freed, V. H., J. Vernetti and M. Montgomery. 1962. The soil behavior of herbicides as influenced by their physical properties. Proc. Western Weed Control Conf., Las Vegas, Nevada. 19:21-36.

Frisse1, M. J. and G. H. Bolt. 1962. Interaction between certain ionizable organic compounds (Herbicides) and clay minerals. Soil Sci. 94:284-291.

Giddings, J. C. 1965. Dynamics of chromatography Part I. Marcel Dekker, Inc. New York. 
Green, R. F., V. K. Yamane and S. R. Obrien. 1968. Transport of atrazine in a latosolic soil in relation to adsorption, degradation and soil water variables. Trans. 9th. Int. Soil Sc. Congr. 1:195-204.

Hamner, C. L., and H. B. Tukey. 1944. Herbicidal action of 2,4-dichlorophenoxyacetic acid and trichlorophenoxyacetic acid on bindweed. Science 100:154-155.

Harris, C. I. 1964. Movement of Dicamba and Diphenamid in soils. Weeds 12:112-115.

- 1966. Adsorption movement and phytotoxicity of Monuron and s-Triazine in Soil. Weeds 14:6-10.

, and G. F. Warren. 1964. Adsorption and desorption of herbicides by soil. Weeds 12:120-126.

Hartley, G. S. 1960. Physicochemical aspects of the availability of herbicides in soils. pp. 63-78. In E. K. Woodford and G. R. Sagar, Herbicides and the soil. Blackwell Science Publications, Oxford, England.

- 1964. Herbicide behavior in the soil. pp. 111-161. In L. J. Audus (ed.). The physiology and biochemistry of herbicides. Academic Press, London.

Hashimoto, I., K. B. Deshpande and H. C. Thomas. 1964. Peclet numbers and retardation factors for ion exchange columns. Eng. Eng. Chem. 3:213-218.

Hernandez, T. P. and G. E. Warren. 1950. Some factors affecting the rate of inactivation and leaching of 2,4-D in different soils. Proc. Amer. Soc. Hort. Sci. 56:287-293.

Hildebrand, E. M. 1946. War on weeds. Science 103:465-468.

Hill, G. D. 1956. Soil factors and herbicide action. Weed Soc. Amer. Abst. pp. 42-43.

Jost, W. 1960. In Diffusion. Academic Press.

Kay, B. D. and D. E. Elrick. 1967. Adsorption and movement of Lindane in soils. Soil Sc. 104:314-322.

Klute, A. 1965. Laboratory measurement of hydraulic conductivity of unsaturated soils. In Methods of Soil Analysis. Agronomy 9:253-261.

, and J. Letey. 1958. The dependence of ionic diffusion on the moisture content of non adsorbing porous media. Soil Sci. Soc. Am. Proc. $22: 213-215$. 
Koren, E., C. L. Foy, and F. M. Ashton. 1969. Adsorption, volatability and migration of throcarbamate herbicides in soil.

Weed Sc. $17: 148-153$.

Kunze, R. J., and D. Kirkham. 1962. Simplified accounting for membrane impedance in capillary conductivity determinations. Soll Sc. Soc. Amer. Proc. 26-421-426.

Lambert, S. M., P. E. Porter and R. H. Schieferstein. 1965. Movement and adsorption of chemicals applied to the soil. Weeds 13:185-190.

Lapidus, L., and N. R. Amundson. 1952. Mathematics of adsorption in beds VI. J. Phys. Chen. 56:984-988.

Lederer, E. and M. Lederer. 1957. Chromatography; a review of principles and applications. Elsevier Pub. Co. New York.

Lindstrom, F. T., R. Haque, V. H. Freed, and Ls Boersma. 1967. Theory on movement of some herbicides in soils. Environmental Sc. Tech. 1:561-565.

Liu, L. C., H. Cibes-Viade and F. K. S. Koo. 1970. Adsorption of Ametryne and Diuron by soils. Weed Sc. 18:470-474.

Logan, A. V., N. R. Odell and V. H. Freed. 1953. The use of $\mathrm{C}^{14}$ in a study of the leaching rate of isopropyl $\mathrm{N}$-phenyl carbamate. Weeds $2: 24-26$.

Martin, A. J. P. and R. L. M. Synge. 1941. A new form of chromatogram employing two liquid phases. I, A theory of chromatography. Biochem. J. $35: 1358-1364$.

Miller, R. J., J. W. Biggar and D. R. Nielsen. 1965. Chloride displacement in panoche clay loam in relation to water movement and distribution. Water Resources Research 1:63-73.

National Agricultural Chemicals Association. 1958. Open door to plenty. NACA, Washington, D. C. 64 p.

Nielsen, D. R. and J. W. Biggar. 1961. Miscible displacement in soils I experimental considerations. Soil Sc. Soc. Amer. Proc. 25:1-5. , and 1963. Miscible displacement IV mixing in glass beads. Soil Sc. Soc. Amer. Proc. 27:10-13.

Oddson, J. K., J. Letey and L. V. Weeds. 1970. Predicted distribution of organic chemicals in solution and adsorbed as a function of position and time for various chemical and soil properties. Soil Sc. Soc. Amer. Proc. 34:412-417. 
Ogle, R. E. and G. F. Warren. 1954. Fate and activity of herbicides in the soil. Weeds $3: 257-273$.

Onsager, Lars. 1931. Reciprocal relations in irreversible process I. Phys. Rev. 37:405-426.

Peaslee, D. E. and R. E. Phillips. 1970. Self diffusion of P in kaolinite treated with $\mathrm{Ca}$ or $\mathrm{NH}_{4}$ salts and with an organic dye. Soil Sc. Soc. Amer. Proc. 34:198-201.

Penman, H. L. 1940. Gas and vapour movements in the soil. J. Agr. Sci. 30:437-461.

Peterson, G. E. 1967. The discovery and development of 2,4-D. Agr. Histor. 41:243-253.

Philip, J. R. 1963a. The theory of dispersal during laminar flow in tubes I. Aust. J. Phys. 16:287-299.

- 1963b. The theory of dispersal during laminar flow in tubes II. Aust. J. Phys. 16:300-310.

Phillips, R. E. 1969. Test of constancy of self-diffusion coefficients. Soil Sc. Soc. Amer. Proc. 33:322-325.

, and D. A. Brown. 1968. Self-diffusion of tritiated water in montmorillonite and kaolimite clays. Soil Sc. Soc. Amer. Proc. 32:302-306.

Phillips, W. M. 1959. Residual herbicidal activity of some chlorosubstituted benzoic acids in soil. Weeds 7:284-294.

Porter, L. K., W. D. Kemper, R. D. Jackson and B. A. Stewart. 1960. Chloride diffusion in soils as influenced by moisture content. Soil Sc. Soc. Amer. Proc. 24:460-463.

Prigogine, I. 1965. Thermodynamics of irreversible processes. Inter-science publishers. New York.

Purne11, H. 1962. Gas chromatography. Academic Press.

Rhee, Hynn-Kee and N. R. Amundson. 1970. An analysis of an adiabatic adsorption column: Part I. Theoretical development.

Chem. Engr. J. 1:241-254.

Roadhouse, F. E. B. and L. A. Birk. 1961. Penetration of and persistence in soil of the herbicide 2-chloro-4, 6-Bis (Ethylamino)S-triazine (simazine). Can. J. Plant Sc. 41:252.

Rolston, D. E., D. Kirkham and D. R. Nielsen. 1969. Miscible displacement of gases through soil columns. Soil Sc. Soc. Amer. Proc. 33:488-492. 
Saddler, L. D. M. 1965. Miscible displacement of soluble salts in reclaiming a salted soil. Soil Sc. 100:348-355.

Scheidegger, A. 1954. Statistical hydrodynamics in porous media. J. App1. Phys. 25:994-1001.

Scott, H. D. and J. F. Lutz. 1971. Release of herbicides from clay minerals as a function of water content: I Kaolinite. Soil Sc. Soc. Amer. Proc. 35:374-379

Sheets, T. J. and C. I. Harris. 1965. Herbicide residues in soils and their phytotoxicities to crops grown in rotation. Residue Reviews. 11:119-140.

Shennan, J. L. and W. W. Fletcher. 1965. The growth in vitro of microorganisms in the presence of substituted phenoxyacetic and phenoxybutyric acids. Weed Res. 5:266-274.

Sherburne, H. R., V. H. Freed and S. G. Gand. 1956. The use of $\mathrm{C}^{14}$ carbony1 labelled 3(p-chloropheny1) 1, 1-dimethyl urea in a leaching study. Weeds 4:50-54.

Snyder, L. R. 1968. Principles of adsorption chromatography. Marce1 Dekker, New York.

Stewart, B. A. and H. V. Eck. 1958. The movement of surface applied nitrate into soils at 5 moisture levels. Soil Sc. Soc. Amer. Proc. 22:260-262.

Swanson, R. A. and G. R. Dutt. 1970. Prediction of atrazine distribution and movement in soil systems. Agronomy Abstracts ASA meetings at Tucson. pp. 100.

Talbert, R. E. and 0. H. Fletcha11. 1965. Adsorption of some S-triazines in soils. Weeds 13:46-51.

Taylor, G. I. 1953. Dispersion of soluble matter in solvent flowing slowly through a tube. Proc. Roy. Soc. (London) A219: 186-203.

Taylor, S. A. and J. W. Cary. 1960. Analysis of simultaneous flow of water and heat with the thermodynamics of irreversible processes. Trans. Intern. Congr. Soil Sc. 7 th Madison 1:80-90. , and - 1964. Linear equations for the simultaneous flov of matter and energy in a continuous soil systen. Soil Sc. Soc. Amer. Proc. 28:167-172.

Timmons, F. L. 1970. A history of weed control in the United States and Canada. Weed Sc. 18:294-307. 
Tyler, K. B., F. E. Broadbent, and B. Kondo. 1958. Nitrogen movement in simulated cross section of field soil. Agronomy J. 50:626-628.

Upchurch, R. P. and W. C. Pierce. 1957. The leaching of Monuron from Lakeland sand soil. Part I, the effect of amount intensity and frequency of simulated rainfall. Weeds 5:321-330.

$$
\text { , and }
$$

. 1958. Leaching of Monuron from Lakeland sand soil. Part II, the effect of soil temperature organic matter, soil moisture and amount of herbicide. Weeds $6: 24-33$.

- 1966. Behavior of herbicides in soil. Residue Reviews 16:46-85.

Weber, J. B., P. W. Perry and R. P. Upchurch. 1965. The influence of temperature and time on the adsorption of paraquat, diquat, 2,4-D and Prometone by clays, charcoal and an anion exchange resin. Soil Sc. Soc. Amer. Proc. 29:678-688.

Wells, H. G. 1961. The outline of history. Sixth Ed. Garden City Books. Garden City, N. Y.

Wilson, J. N. 1940. A theory of chromatography. J. Amer. Chem. Soc. $62: 1583-1591$.

Yang, M. S. 1966. Simultaneous movement of water and herbicides in unsaturated soils. Unpublished M.S. Thesis, Utah State University Library. Logan.

Yost, T. F. 1940. Summary of bind weed situation and progress in 1939. Kansas State Board Agr. Rep. 237., 73 p. 


\section{BIOGEAPHICAL SIETCH}

Veerabhadrappa Jyothi was born in Holalu Nysore State, India on December 21, 1936. He attended Government High School, Harapanahalli Mysore State from which he graduated in Jure, 1955. He entered Karnatak University Dharwar to study Agriculture and earned a B. S. degree with honors. Upon graduation he was taken on the teaching faculty to teach Agricultural Engineering at the College of Agriculture Dharwar. He was on the faculty for 5 years and then entered Utah State University in 1965 and earned M. S. degree in Soil Physics in 1967 under the guidance of the late Dr. Sterling A. Taylor.

In January, 1969, he was adritted to the Graduate School of the University of Florida.

The author is married to the former Miss M. C. Ambujakshi and they have two children: Prashant and Pratima.

The author is a member of the American Society of Agronomy, Soil Science Society of America and the honorary society of Gamma Sigma Delta. 
I certify that I have read this study and that in my opinion it conforms to acceptable standards of scholarly presentation and is fully adequate, in scope and quality, as a dissertation for the degree of Doctor of Philosophy.

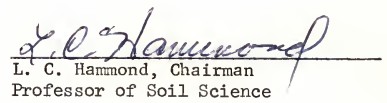

I certify that I have read this study and that in my opinion it conforms to acceptable standards of scholarly presentation and is fully adequate, in scope and quality, as a dissertation for the degree of Doctor of Philosophy.

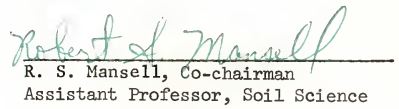

I certify that I have read this study and that in my opinion it conforms to acceptable standards of scholarly presentation and is fully adequate, in scope and quality, as a dissertation for the degree of Doctor of Philosophy.

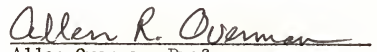

Allen Overman, Professor Agricultural Engineering

I certify that I have read this study and that in my opinion it conforms to acceptable standards of scholarly presentation and is fully adequate, in scope and quality, as a dissertation for the degree of Doctor of Philosophy.

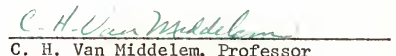
C. H. Van Middelem, Professor Food Science Department 
I certify that I have read this study and that in my opinion it conforms to acceptable standards of scholarly presentation and is fully adequate, in scope and quality, as a dissertation for the degree of Doctor of Philosophy.

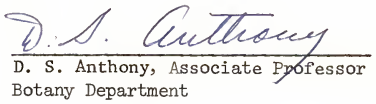

I certify that I have read this study and that in my opinion it conforms to acceptable standards of scholarly presentation and is fully adequate, in scope and quality, as a dissertation for the degree of Doctor of Philosophy.

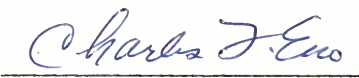

C. F. Eno, Professor and Chairman Soil Science Department

This dissertation was subnitted to the Dean of the College of Agriculture and to the Graduate Council, and was accepted as partial fulfillment of the requirements for the degree of Doctor of Philosophy.

August, 1971

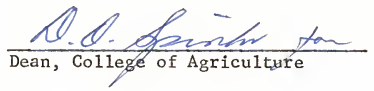

